\title{
Actividades privadas compatibles de los altos cargos en la Administración General del Estado*
}

José María Pérez Monguió

DOI: https://doi.org/10.47623/ivap-rvap.109.2017.1.06

\begin{abstract}
Sumario: I. Introducción y sistemática. - II. El régimen de las actividades compatibles privadas en la Ley $3 / 2015$, de 30 de marzo, reguladora del ejercicio del alto cargo de la Administración General del Estado.-III. Administración del patrimonio personal o familiar: 1. Limitaciones patrimoniales en participaciones societarias. A) Participaciones superiores a un $10 \%$ en empresas, en tanto que tengan conciertos o contratos de cualquier naturaleza con el sector público. B) Participación en empresas que reciban subvenciones provenientes de la Administración C) Participación en una empresa subcontratista de otra que tenga contratos de cualquier naturaleza con el sector público. D) Regularización del alto cargo en cuanto al cumplimiento de las limitaciones en participaciones societarias. 2. Control y gestión de valores y activos financieros. A) Ámbito subjetivo. B) Contenido material. C) Excepciones. -IV. Producción y creación literaria, artística, científica o técnica y las publicaciones derivadas de aquéllas. $-V$. Colaboración y la asistencia ocasional y excepcional como ponente a congresos, seminarios, jornadas de trabajo, conferencias o cursos de carácter profesional. -VI. Participación en entidades culturales o benéficas. - VII. Bibliografía.
\end{abstract}

\section{Introducción y sistemática}

El ejercicio de la actividad de un alto cargo se desarrolla en el marco de un conjunto de principios y exigencias establecidas actualmente, entre otras normas, en Ley 19/2013, de 9 de diciembre, de transparencia, acceso a la información pública y buen gobierno(1) y

\footnotetext{
* Trabajo realizado en el marco del Proyecto DER2016-77513-R: Financiado AEI y FEDER, Ministerio de Economía, Industria y Competitividad.

(1) La Ley 19/2013 distingue entre principios generales y principios de conducta en el artículo 26.2. Véase sobre los citados principios, J. M. ${ }^{a}$ PÉREZ MONGUIÓ y S. FERNÁNDEZ RAMOS, Tansparencia, acceso a la información pública y buen gobierno, Thomson-Reuter Aranzadi, Cizur
} 
en la Ley $3 / 2015$, de 30 de marzo, reguladora del ejercicio del alto cargo de la Administración General del Estado. Unos principios y exigencias que se han ido desarrollando e implementando desde unos pilares básicos, ya recogidos, en algún caso de forma embrionaria, en la Ley 25/1983, de 26 de diciembre, sobre incompatibilidades de altos cargos, como son, entre otros muchos, los de imparcialidad, dedicación exclusiva, retribución única y todo ello en el marco del principio de Buena Administración.

Con todo, desde la Ley de incompatibilidades de los altos cargos de los años ochenta se han venido contemplando en las distintas leyes excepciones que permitían atenuar algunos principios como el de dedicación y retribución única, facilitando el desarrollo de ciertas actividades que podían compatibilizarse con el desarrollo del cargo y que se han clasificado en públicas y privadas.

Así el propio artículo 13 de la Ley 3/2015, de 30 de marzo, reguladora del ejercicio del alto cargo de la Administración General del Estado parte de una negación absoluta de compatibilidad para después proceder a recoger las excepciones, cuando dispone que "Los altos cargos ejercerán sus funciones con dedicación exclusiva y no podrán compatibilizar su actividad con el desempeño, por sí, o mediante sustitución o apoderamiento, de cualquier otro puesto, cargo, representación, profesión o actividad, sean de carácter público o privado, por cuenta propia o ajena. Tampoco podrán percibir cualquier otra remuneración con cargo a los presupuestos de las Administraciones públicas o entidades vinculadas o dependientes de ellas, ni cualquier otra percepción que, directa o indirectamente, provenga de una actividad privada simultánea».

Los argumentos para relajar el severo régimen de incompatibilidad de los altos cargos son diversos para los supuestos de actividades públicas y privadas.

En el primer caso, el principal motivo puede residir en la posibilidad de emplear al alto cargo en otras actividades de naturaleza pública que permitan optimizar al máximo las capacidades y habilidades $y$, entre ellas se prevén: a) El desempeño de los cargos que les correspondan con carácter institucional, de aquellos para los que sean comisionados por el Gobierno, o de los que fueran designados por su propia condición; b) El desarrollo de misiones temporales de representación ante

Menor, 2014, pp. ; J. JUSTO MEGÍAS QUIRÓS, "Regeneración democrática de los altos cargos», en A. TRONCOSO REIGADA, Comentario a la Ley de Transparencia, Acceso a la Información Pública y Buen Gobierno, Civitas-Thomson Reuter, 2017, pp. 1505 a 1528 y M. M. SERRANO PÉREZ, "Los principios de actuación del buen gobierno, en A. TRONCOSO REIGADA, Comentario a la Ley de Transparencia, Acceso a la Información Pública y Buen Gobierno, Civitas-Thomson Reuter, 2017, 1529-1565. 
otros Estados, o ante organizaciones o conferencias internacionales. $c$ ) El desempeño de la presidencia de las sociedades a las que se refiere el artículo 166.2 de la Ley $33 / 2003$, de 3 de noviembre, del Patrimonio de las Administraciones Públicas, cuando la naturaleza de los fines de la sociedad guarden conexión con las competencias legalmente atribuidas al alto cargo, así como la representación de la Administración General del Estado en los órganos colegiados, directivos o consejos de administración de organismos o empresas con capital público o de entidades de Derecho Público.

En el caso de la compatibilidad con algunas actividades privadas el propósito es bien distinto $y$, esencialmente, tiene como objeto principal evitar fallecimiento civil, esto es que el cargo termine por fagocitar a la persona. De esta manera, se permite el desarrollo, por una parte, de actividades para la administración del patrimonio personal y familiar, y por otra el desarrollo de determinadas actividades muy específicas y con un mayor número de limitaciones que las actividades públicas.

El objeto de este trabajo será precisamente el análisis del régimen de este último tipo de compatibilidades, esto es las privadas, tomando como piedra angular la Ley $3 / 2015$, de 30 de marzo, reguladora del ejercicio del alto cargo de la Administración General del Estado, con el propósito de ver los avances o retrocesos que se hayan podido producir con arreglo a la normativa estatal anterior. Esta perspectiva no será un obstáculo para acudir también a la legislación autonómica sobre altos cargos, aunque también se recurrirá a la normativa de transparencia y buen gobierno pues, por ejemplo, la compatibilidad de los altos cargos se han regulado en la Ley $1 / 2016$, de 18 de enero, de transparencia y buen gobierno de la Comunidad Autónoma de Galicia, todo ello con el fin de poder realizar comparaciones que permitan extraer las aportaciones que se han efectuado en esta materia.

\section{El régimen de la actividades compatibles privadas en la Ley $3 / 2015$, de 30 de marzo, reguladora del ejercicio del alto cargo de la Administración General del Estado}

Ley $3 / 2015$, de 30 de marzo, reguladora del ejercicio del alto cargo de la Administración General del Estado prevé, como hicieron la Ley 12/1995, de 11 de mayo, de incompatibilidades de los miembros del Gobierno de la Nación y de los Altos Cargos de la Administración General del Estado y la Ley 5/2006, de 10 de abril, de regulación de los conflictos de intereses de los miembros del Gobierno y de los Altos Cargos de la Administración General del Estado, la compatibilidad del ejercicio de un puesto de alto cargo con una serie de actividades pri- 
vadas (2), sin perjuicio de la previsión del artículo 8 de la Ley 25/1983, de 26 de diciembre, sobre incompatibilidades de altos cargos. Esta compatibilidad ha estado sujeta a que el desarrollo de las mismas no comprometiese la imparcialidad o independencia en el ejercicio o desempeño del cargo.

El ejercicio de las actividades privadas permitidas, que tiene un carácter tasado, está sujeto a que no puedan afectar o comprometer la imparcialidad e independencia pero incluso en los casos en que esto no suceda, el principio de jerarquía administrativa (3) puede suponer o puede llegar a limitar el desarrollo de las actividades privadas inicialmente compatibles. Esta posibilidad esencialmente se podría producir o consumar, como expondré, en las actividades contempladas en los apartados 13.2.c).1. ${ }^{a}$ y 2. ${ }^{a}$, entre las que se hallan las de producción y creación artística, literaria, científica o técnica y las publicaciones derivadas de aquellas, así como la colaboración y la asistencia ocasional y excepcional como ponente a congresos o la participación en entidades culturales o benéficas. Todo ello en la medida que puede suceder que determinadas actividades privadas compatibles sean susceptibles de provocar una situación no deseable o, basta que así lo considere el superior, para la Administración, pensemos por ejemplo la participación en determinados foros o determinadas publicaciones que no resulten adecuadas o convenientes u oportunas. Sin embargo, no tiene cabida en el ámbito de la mera administración del patrimonio personal o familiar pues en este caso entraría en el campo más bien del conflicto de interés.

(2) Arts. 4 Ley $12 / 1995$ y 10 Ley 5/2006.

(3) La Ley 5/2006, de 10 de abril, de regulación de los conflictos de intereses de los miembros del Gobierno y de los Altos Cargos de la Administración General del Estado introdujo un nuevo matiz, que ahora reproduce la Ley $3 / 2015$, al incluir la expresión «sin perjuicio del principio de jerarquía administrativa». Este inciso fue incluido durante la tramitación parlamentaria. Véase la enmienda 28 del Grupo Parlamentario Popular en el Congreso (BOCG Congreso de los Diputados, serie A, núm. 25-5, de 26 de abril de 2005). 


\section{Actividades privadas compatibles}

\begin{tabular}{|c|c|c|}
\hline $\begin{array}{l}\text { Requisitos previos } \\
\text { comunes }\end{array}$ & Actividad & Requisitos específicos \\
\hline \multirow[t]{4}{*}{$\begin{array}{l}\text { La actividad no puede } \\
\text { comprometer la impar- } \\
\text { cialidad o independen- } \\
\text { cia del alto cargo en el } \\
\text { ejercicio de su función. }\end{array}$} & $\begin{array}{l}\text { Las de mera administración del } \\
\text { patrimonio personal o familiar } \\
\text { con las limitaciones estableci- } \\
\text { das en la presente ley. }\end{array}$ & $\begin{array}{l}\text { Participaciones societa- } \\
\text { rias: art. } 14 . \\
\text { Control y gestión de va- } \\
\text { lores y activos financie- } \\
\text { ros: art. } 18 .\end{array}$ \\
\hline & $\begin{array}{l}\text { Producción y creación literaria, } \\
\text { artística, científica o técnica y } \\
\text { las publicaciones derivadas de } \\
\text { aquellas }\end{array}$ & \multirow{2}{*}{$\begin{array}{l}\text { No pueden ser conse- } \\
\text { cuencia de una relación } \\
\text { de empleo, o de pres- } \\
\text { tación de servicios, o } \\
\text { suponer un menoscabo } \\
\text { del estricto cumplimien- } \\
\text { to de sus deberes. }\end{array}$} \\
\hline & $\begin{array}{l}\text { Colaboración y asistencia oca- } \\
\text { sional y excepcional como po- } \\
\text { nente a congresos, seminarios, } \\
\text { jornadas de trabajo, conferen- } \\
\text { cias o cursos de carácter profe- } \\
\text { sional. }\end{array}$ & \\
\hline & $\begin{array}{l}\text { Participación en entidades cul- } \\
\text { turales o benéficas que no ten- } \\
\text { gan ánimo de lucro o en funda- } \\
\text { ciones. }\end{array}$ & $\begin{array}{l}\text { No pueden percibir nin- } \\
\text { gún tipo de retribución, } \\
\text { sin perjuicio del derecho } \\
\text { a ser reembolsados de } \\
\text { los gastos debidamen- } \\
\text { te justificados que el } \\
\text { desempeño de su fun- } \\
\text { ción les ocasione con- } \\
\text { forme a lo previsto en } \\
\text { el artículo } 3.5 \text { de la Ley } \\
49 / 2002 \text {. }\end{array}$ \\
\hline
\end{tabular}

\section{Administración del patrimonio personal o familiar}

La Ley 3/2015 prevé como una de las actividades compatibles la «mera administración del patrimonio personal o familiar con las limitaciones establecidas en la presente Ley" - art. 13.2.c).1. ${ }^{\mathrm{a}}-$. Sin entrar a fondo en la valoración de la medida, pues resulta razonable, como ha puesto de manifiesto SARMIENTO MÉNDEZ, que la persona que accede a la condición 
de alto cargo pueda continuar con la administración de su patrimonio (4) pues no sería lógico que se le impidiese la supervisión de sus intereses económicos (5).

En este sentido, la Sentencia delTribunal Superior de Justicia de las Islas Baleares de 11 de junio de 2014 (JUR/2014, 162671) manifiesta que «De entenderse que cualquier relación entre la función pública a la que se pretende acceder y la profesión que se ejercía, es por sí solo determinante de incompatibilidad, resultaría que sólo los ciudadanos con nulo pasado profesional, pueden acceder a un cargo público. O lo que es lo mismo: sólo pueden acceder los profesionales de la política. La interpretación de la norma ha de permitir el acceso a la vida pública a profesionales de la actividad privada porque ello redunda en beneficio de la sociedad, que se vería privada de poder tener gestores y dirigentes altamente cualificados en su distintos campos profesionales, y además, un ente tras una interpretación tan restrictiva y constrictora, constituiría una interpretación disuasoria para aquéllos, porque en su caso acceder a la vida pública les comportaría un quebranto absoluto en su vida, de forma que al fin se traduciría en una discriminación intolerable e incompatible con lo dispuesto en el artículo 23.2 de la Constitución».

Al margen de esta consideración, lo cierto es que la redacción no es muy adecuada, aunque sea la misma que se recoge desde hace décadas en la legislación estatal y la mayoría de las disposiciones autonómicas (6).

(4) La Sentencia del Tribunal Superior de Justicia de las Islas Baleares de 11 de junio de 2014 (JUR/2014, 162671) entiende que el patrimonio empresarial o comercial sí que puede integrarse en la excepción del patrimonio personal o familiar, cuya mera administración no es incompatible con el cargo público. Resultan de interés los argumentos que esgrime para entender que no existe incompatibilidad en el ejercicio de un alto cargo con la propiedad de una oficina de farmacia (F. J. 3. ${ }^{\circ}$ ).

(5) X. A. SARMIENTO MÉNDEZ, "As incompatibilidades dos membros da Xunta e demáis altos cargos", en Revista Xurídica de la Universidad de Santiago de Compostela, núm. 1 (1996), p. 345.

(6) Véanse también, entre otros, los artículos 8.1.d) Ley 13/2005, de 27 de diciembre, del régimen de incompatibilidades de los altos cargos al servicio de la Generalidad -en esta comunidad no se emplea el término "mera" sino que se recurre al término "simple» - (en el mismo sentido del art. 42.a) Ley $1 / 2016$, de 18 de enero, de transparencia y buen gobierno de la Comunidad de Galicia-, 11.a) Ley de Cantabria 1/2008, de 2 de julio, reguladora de los conflictos de intereses de los miembros del Gobierno y de los altos cargos de la Administración de Cantabria, 56.a) Ley 8/2003, de 28 de octubre, del Gobierno e Incompatibilidades de sus miembros de La Rioja 8/2003; art. 7.2.e) Ley 3/2016, de 30 de noviembre, del Estatuto de los Altos Cargos de la Administración de la Comunidad de Castilla y León; 7.a) Ley 2/1996, 19 noviembre, de incompatibilidades de los miembros del Gobierno y altos cargos de la comunidad autónoma de las Illes Balears.; 8.1 Ley 3/1997, de 8 de mayo, de Incompatibilidades de los miembros del Gobierno y altos cargos de la Comunidad Autónoma de Canarias; 6 Ley 19/1996, de 4 de noviembre, de Incompatibilidades de los Miembros del Gobierno de Navarra y de los Altos Cargos de la Administración de la Comunidad Foral de Navarra y 7.1.e) Ley 8/2016, de 28 de octubre, de la Generalitat Valenciana, de Incompatibilidades y Conflictos de Intereses de Personas con Cargos Públicos no Electos o 7.2.e) Ley 8/2016, de 28 de octubre, de incompatibilidades y conflictos de intereses de personas con cargos públicos no electos de la Generalidad Valenciana. La Ley $1 / 2014$, de 18 de febrero, de regulación del estatuto de los cargos públicos del Gobierno y la 
Así como ha dejado de manifiesto MESEGUER YEBRA(7), el término "mera» debe entenderse como una restricción del alcance de lo que es, en efecto, una pura excepción (8) que es calificada por SÁNCHEZ BLANCO como una expresión poco afortunada (9).

Esta actividad compatible se encuentra, con una redacción idéntica, en la Ley $12 / 1995$ - art. 4.a) - y en la Ley 5/2006 - art. 10.a) - con la única excepción de que la norma del 2006 se refería a las limitaciones establecidas en el artículo 6, esto es, el relativo a las limitaciones patrimoniales en participaciones societarias (10). Sin embargo, vinculado a esta materia se encuentra el control y gestión de valores y activos financieros, cues-

Administración de la Comunidad Autónoma de Extremadura ha mejorado técnica y conceptualmente esta causa de compatibilidad cuando dispone que será compatible el ejercicio del cargo "con las actuaciones que se deriven de la administración de su patrimonio personal o de la unidad familiar o las no retribuidas que pudieran realizarse profesionalmente en relación con dicha unidad familiar salvo en el supuesto de participación en el capital de empresas y sociedades...» - art. 29.1.c)—.

(7) J. MESEGUERYEBRA, Conflictos de Intereses e incompatibilidades de los miembros del Gobierno y Altos Cargos de la Administración, Bosch, Barcelona, 2007. p. 193.

(8) El Grupo Parlamentario Popular propuso eliminar el término en la enmienda 29 al proyecto de la que fuese la Ley 5/2006 (BOCD Serie A. núm. 25-5, de 26 de abril de 2005).

(9) A. JIMÉNEZ BLANCO, "Estatuto de los miembros del Gobierno: deberes, derechos e incompatibilidades", en AA. VV. (Coord. L. PAREJO ALFONSO), Estudios sobre el Gobierno, Universidad Carlos III y BOE, Madrid, 1996, p. 226. Algunos autores han criticado el empleo del verbo administrar por entender que en el orden jurídico civil se contrapone a disponer y, por tanto, se podría llegar al absurdo de que un ministro no pudiera vender un inmueble de su propiedad. Desde nuestra posición esta interpretación debe ser rechazada pues administrar, en la tercera acepción del Real Diccionario de la Lengua Española, se define como «Ordenar, disponer, organizar, en especial la hacienda o los bienes" y, por tanto, entendemos que la administración también lleva implícita la disposición de los bienes que integran el patrimonio. Véase, J. MESEGUER YEBRA, Régimen de conflictos..., ob. cit., pp. 193-194. El artículo 7.1.d) de la Ley 8/2016, de 28 de octubre, de la Generalitat, de Incompatibilidades y Conflictos de Intereses de Personas con Cargos Públicos no Electos "Las derivadas de la simple administración de su patrimonio personal o familiar...", al igual que el artículo 42.1.a) Ley $1 / 2016$, de 18 de enero, de transparencia y buen gobierno de la Comunidad Autónoma de Galicia.

(10) En el artículo 5 de la Ley 3/2005, de 8 de abril, de Incompatibilidades de Altos Cargos de la Administración de la Junta de Andalucía y de Declaración de Actividades, Bienes e Intereses de Altos Cargos y otros Cargos Públicos, bajo la rúbrica Compatibilidad con la administración del patrimonio personal o familiar, se contemplan conjuntamente las limitaciones de participación en empresas cuando se dispone que "Las actividades derivadas de la mera administración del patrimonio personal o familiar no están sujetas a lo dispuesto en el artículo 3, salvo el supuesto de participación superior al $10 \%$ entre el titular del alto cargo, su cónyuge, pareja de hecho inscrita en el correspondiente Registro, hijos menores y personas tuteladas en el capital de sociedades que tengan conciertos, contratos o concesiones de cualquier naturaleza con el sector público estatal, autonómico o local" y el artículo 7.2.e) Ley $3 / 2016$, de 30 de noviembre, del Estatuto de los Altos Cargos de la Administración de la Comunidad de Castilla y León permite "La administración del patrimonio personal o familiar, siempre que no ostente por sí o junto con su cónyuge, sea cual sea el régimen económico matrimonial, o con persona con quien conviva con análoga relación de afectividad, participaciones directas o indirectas, iguales o superiores a un diez por ciento, o que sin llegar a este porcentaje supongan una posición en el capital social que pueda condicionar de forma relevante su actuación, en empresas o entidades que tengan contratos, conciertos o convenios con el sector público estatal, autonómico o local». 
tión a la que la Ley 5/2006 dedicaba el artículo 13(11), pero al hacer mención, esta última exclusivamente al citado artículo 6 , parecía que quedaban excluidos del control y gestión de activos financieros, cuando realmente forman parte del patrimonio personal.

De esta manera, al hacer referencia la Ley 3/2015 de forma genérica «a las limitaciones establecidas en la Ley", realiza una mejora técnica en esta cuestión, aunque también es cierto que podía haber incluido ambos artículos, esto es el 14 y el 18, en la redacción de la actividad compatible de administración del patrimonio personal o familiar siguiendo el ejemplo de la Ley País Vasco 1/2014 que expresamente remite a los artículos 22, Limitaciones patrimoniales en participaciones societarias y 23, Control y gestión de valores y de activos financieros - art. 14.1.a)-.

\section{Limitaciones patrimoniales en participaciones societarias}

Esta limitación tiene como objetivo evitar, por una parte, el conflicto de interés que podría provocar la tenencia de participaciones societarias y, por otra, remover aquellas actividades que podrían afectar al principio de dedicación exclusiva que planea sobre el ejercicio de las funciones desarrolladas o desempeñadas por un alto cargo, prevista en el artículo 13 de la Ley 3/2015. Su antecedente inmediato se halla en el artículo 6 de la Ley $5 / 2006$, aunque las diferencias son significativas como tendremos ocasión de ver, tanto en su dimensión subjetiva como objetiva.

De esta manera, el artículo 14 contempla tres supuestos generales en los que los altos cargos tendrán una limitación patrimonial en participaciones societarias, con las particularidades que veremos en los siguientes epígrafes: a) participaciones superiores a un $10 \%$ en empresas, en tanto que tengan conciertos o contratos de cualquier naturaleza con el sector público, b) Participación en empresas que reciban subvenciones provenientes de la Administración y $c$ ) Participación en una empresa subcontratista de otra que tenga contratos de cualquier naturaleza con el sector público. Con carácter previo al análisis de estas limitaciones es oportuno adentrarnos en el ámbito subjetivo de la limitación, que no prohibición, pues dentro de los límites previstos no existe ninguna limitación.

La Ley 3/2015 prevé que "los altos cargos no podrán tener, por sí o por persona interpuesta - entendiéndose esta como persona física o jurídica que actúa por cuenta del alto cargo- participaciones directas o indirectas superiores a un diez por ciento en empresas en tanto que tengan concier-

(11) El citado precepto era a su vez una reproducción del artículo 7 de la Ley 12/1995. 
tos o contratos de cualquier naturaleza con el sector público estatal, autonómico o local...".

La primera cuestión que sobresale, como señaló el Consejo de Estado en su Dictamen 1435/2013, de 6 de febrero de 2014, es que el ámbito subjetivo del régimen de limitación patrimonial en participaciones societarias es más limitado, en tanto que la redacción proscribe la tenencia de participaciones al alto cargo "por sí o por persona interpuesta», expresión que ha sustituido a la referencia que el artículo 6.1 de la Ley 5/2006 contenía al alto cargo «por sí o junto con su cónyuge, sea cual sea el régimen económico matrimonial, o persona que conviva en análoga relación de afectividad e hijos dependientes y personas tuteladas" (12). Continúa el Consejo de Estado manifestando que "Se dice que parece ser más limitado porque se aprecia cierta ambigüedad en la redacción del precepto en la medida en que la referencia anterior «junto con cónyuge», sea cual sea el régimen económico matrimonial, persona que conviva en análoga relación de afectividad, hijos dependientes y personas tuteladas se aludía a un criterio para computar el volumen de la participación mientras que la referencia a la persona interpuesta es una precisión relativa al concepto de tenencia» (13).

De esta manera, el órgano consultivo recomendaba aclarar si la expresión "persona interpuesta" debe entenderse referida al "tercero independiente" al que se refiere el artículo 14.3, o a la entidad financiera encargada de la gestión y administración de las acciones y participaciones del alto cargo prevista en el artículo 18.1 del por entonces anteproyecto. Lo cierto es que no queda especialmente clara esta cuestión, pues el artículo 14.3 cuando se refiere al tercero independiente, entiende "como tal a un sujeto en el que no concurren las circunstancias contempladas en el apartado $1 \%$.

(12) El Grupo Parlamentario de Unión Progreso y Democracia en el Congreso, en la enmienda núm. 12, solicitó la modificación del artículo 14.1 con el fin de revisar la redacción del artículo 6 de la Ley 5/2006. La propuesta concreta, que no fue admitida, era la siguiente: "1. Los altos cargos no podrán tener, por sí, por persona interpuesta, ni por personas vinculadas tales como su cónyuge, sea cual sea el régimen económico matrimonial, o persona que conviva en análoga relación de afectividad e hijos dependientes y personas tuteladas, familiares hasta cuarto grado de consanguinidad, participaciones directas o indirectas superiores a un diez por ciento en empresas, en tanto que tengan conciertos o contratos de cualquier naturaleza, con el sector público estatal, autonómico o local, o que reciban subvenciones provenientes de cualquier Administración Pública».

(13) La extensión de la limitación al cónyuge, hijos y personas tuteladas es común en la legislación de incompatibilidades autonómica. Véanse, entre otros, los artículos 5 Ley Andalucía 3/2005; 17.1 Ley Cantabria 1/2008; 5.1.a) Ley Asturias 4/1995; 4.3 Ley Cataluña 13/2005 - extiende la medida a demás familiares de primer grado de consanguinidad o afinidad-; 4.3 Ley Canarias 3/1997 -esta última no incluye a los hijos o personas dependientes- o 4.3 Ley Comunitat Valenciana 8/2016, que incluye también a las parejas de hecho o situaciones de análoga convivencia y en el mismo sentido 7.2.e) Ley Castilla y León 3/2016. 
Por último, el Consejo de Estado instaba al Gobierno a precisar si el volumen de participación previsto en el apartado 1 del artículo 14 -esto es, el diez por ciento- debía calcularse sumando automáticamente a las participaciones propias las del cónyuge e hijos dependientes o solo cuando éstos puedan ser considerados persona interpuesta, si es que así fuera. En este sentido, la redacción del precepto parece que no ofrece duda alguna, pues se dispone que "los altos cargos no podrán tener, por sí o por persona interpuesta, participaciones...", y, en consecuencia estimamos que solo podrán sumarse los porcentajes cuando pueda demostrarse que aquellas tienen la condición de personas interpuestas. En este sentido, consideramos más acertada la fórmula de la Ley $5 / 2006$, que partía de la premisa de que las participaciones del cónyuge en sentido amplio, hijos dependientes y personas tuteladas se incluían directamente en el porcentaje del alto cargo. La opción de la Ley 5/2006 tampoco era perfecta pues en ella eran excluidas todas aquellas personas interpuestas que no fueran las anteriores. Por ello, entendemos que debería haberse mantenido la formulación anterior que funcionaba como una presunción iure et de iure, e incluir la figura de la persona interpuesta, que puede englobar incluso personas jurídicas o físicas, pero en este caso tendría que demostrarse el carácter interpuesto. La opción que mantenemos es muy estricta pero, con la redacción actual, en la que la superación de los porcentajes previstos del $10 \%$ no supone la obligación de enajenar las participaciones superiores, lo cierto es que el alto cargo no pierde ni se desprende de su patrimonio (14), pues como expondré, la enajenación

\section{A. Participaciones superiores a un 10\% en empresas, en tanto QUe tengan CONCIERTOS O CONTRATOS DE CUALQUIER NATURALEZA CON EL SECTOR PÚBLICO}

Esta limitación, que exclusivamente es efectiva "en tanto que tengan - las empresas - conciertos o contratos de cualquier naturaleza con el sector público" ya se encontraba en el artículo 6.1 de la Ley 5/2006(15). La única diferencia se encuentra en el elemento subjetivo que hemos analizado en el epígrafe anterior. Esto es, que se ha pasado hacer girar el límite previsto sobre el titular del alto cargo, su cónyuge, sea cual sea el régimen económico matrimonial, o persona que conviva en análoga relación de afectividad e hijos dependientes y personas tuteladas por el alto cargo y personas interpuestas.

(14) Véanse las reflexiones de J. MESEGUER YEBRA, Régimen de conflictos de intereses e incompatibilidades..., ob. cit., pp. 117-120.

(15) Véase, sobre conflicto de intereses y contratación, el interesante trabajo de A. CERRILLO MARTíNEZ, El Principio de Integridad en la Contratación Pública, Thomson-Aranzadi, 2014. 
El límite del 10\%, común en la legislación autonómica de conflicto de intereses (16), fue criticado durante la tramitación parlamentaria de la Ley 3/2015, llegando a solicitar, sin éxito, el Grupo Parlamentario Mixto en el Congreso, su eliminación bajo la premisa de que «La participación en una sociedad que tiene vinculación con el sector público (conciertos o contratos), aunque mínima, puede influir en la decisión de un alto cargo" (17). Esta limitación exclusivamente perdura durante el tiempo en que dura el concierto o contrato de cualquier naturaleza con el sector público (18).

Sin embargo, como bien ha señalado MESEGUER YEBRA, una cantidad inferior al diez por ciento no supone o significa que no se pueda tener el control efectivo de la empresa, sobre todo en los casos de grandes compañías, en las que suele ser improbable que quien ostente el poder tenga participaciones muy amplias. De esta manera, el ar-

(16) Véanse, p. e., arts. 5 Ley Andalucía 3/2005; 4.2 Ley Baleares 2/1996; 4.1 Ley Canarias 3/1997; 8 Ley Cataluña 13/2005; 5.1.a) Ley Asturias 4/1995; 17.2 Ley Cantabria 11/2008 o 3.2 Ley Navarra 19/1996. Resulta muy interesante el artículo 4 de la Ley Comunitat Valenciana 8/2016 cuando exceptúa este límite cuando "las acciones o participaciones de las que la persona sea propietaria por formar parte de un establecimiento mercantil familiar y que hayan estado en su poder por lo menos los cinco años anteriores a su nombramiento o, si la transmisión se produce por causa de muerte, en un período inferior o durante el mismo mandato. En este caso, la persona afectada durante el mandato no podrá ejercer ningún cargo de gerencia o administración de la empresa, se limitará únicamente a mantenerse como propietaria de las acciones y estará sujeta a los deberes del artículo 6 y del apartado 2 de este artículo", al igual que tampoco se aplicará a las "cooperativas de trabajo asociado ni cooperativas agrícolas, de consumo o de aprovechamiento energético».

(17) Véase enmienda 42 (BOCD Serie A núm. 83-2, 9 de diciembre de 2014).

(18) Ley Andalucía 3/2005 recoge una excepción al régimen de compatibilidad para la administración del patrimonio personal o familiar en los supuestos de «participación superior al diez por ciento entre el titular del alto cargo, su cónyuge, pareja de hecho inscrita en el correspondiente Registro, hijos menores y personas titulares en sociedades que tengan conciertos, contratos o concesiones de cualquier naturaleza con el sector público estatal, autonómico o local». Una previsión similar ya se encontraba en la Ley del 84. Sin embargo, la redacción actual ha mejorado notablemente la anterior en la medida que la primera no contemplaba a las parejas de hecho y personas tuteladas y sólo se producían en los supuestos en que la participación fuera superior al $10 \%$ en las sociedades que tengan conciertos de obras, servicios o suministros, sea cual sea su naturaleza, exclusivamente cuando aquéllos fueran con la entidad pública en la que desempeñase su cargo, mientras que con la ley vigente esta limitación ha sido eliminada, ampliándose a todo el sector público estatal, autonómico o local. Esta cautela se ha visto reforzada, en cierta medida, con la obligación que se impone en el artículo 9 de la Ley Andalucía 3/2005, que es una reproducción del artículo 8 de la Ley Andalucía $5 / 1984$, a las empresas, entidades o sociedades que tomen parte en licitaciones públicas, contraten o hayan de encargarse de la gestión de cualquier servicio público, ya sea prestado directamente por la Administración de la Junta de Andalucía o a través de sus entes instrumentales, de acreditar, mediante la oportuna certificación expedida por su órgano de dirección o representación competente, que no forma parte de los órganos de gobierno o administración a ninguna persona que se encuentre en las situaciones referidas en esta disposición. El incumplimiento de este requisito supondrá el rechazo de las proposiciones que no acompañen dicha certificación, junto a los documentos requeridos en cada caso. De esta manera, se articula un nuevo instrumento, al margen de las propias declaraciones exigidas por la Ley a los altos cargos, para la detección de posibles participaciones de altos cargos en sociedades que participen empresas, entidades o sociedades que tomen parte en licitaciones públicas, contraten o hayan de encargarse de la gestión de cualquier servicio público, ya sea prestado directamente por la Administración de la Junta de Andalucía o a través de sus entes instrumentales. 
tículo 14.2 de la Ley 3/2015, siguiendo el sendero del artículo 6.1 de la Ley 5/2006, relaja a la mínima el requisito general del porcentaje para los supuestos en los que las empresas tengan la forma de sociedad anónima con un capital suscrito superior a 600.000 euros, en cuyo caso, las participaciones patrimoniales del alto cargo, no tienen que llegar al $10 \%$, pues bastará con que su porcentaje pueda condicionar de forma relevante su actuación - art. 14.2-(19), esto es, lo que se conoce como capital de control (20).

Esta medida debe ser calificada como positiva por recoger una realidad y una posibilidad. Sin embargo, lo cierto es que la misma reposa o gira sobre un concepto jurídico indeterminado como es el de "una posición en el capital social de la empresa que pueda condicionar de forma relevante su actuación", que genera muchas dudas. Y como mantiene MESEGUER YEBRA «dicha estimación sólo puede efectuarse con rigor tomando en cuenta aspectos como el ámbito sectorial del mercado en el que actúa la sociedad, el número y capacidad de los competidores en el sector, el grado de intervencionismo público en el mismo, la dispersión accionarial en el capital...»(21).

\section{B) Participación en EMPRESAS QUe RECIBAN SUBVEnCIONES PROVENIENTES DE LA ADMINISTRACIÓN}

La segunda de las limitaciones se extiende a los altos cargos que tengan participaciones en empresas que reciban subvenciones "provenientes de cualquier administración pública». De la redacción de la limitación lo único que resulta claro es el hecho de que la subvención puede provenir de cualquier administración pública y no, como se exigía anteriormente, de la Administración General del Estado - art. 6.1 in fine Ley 5/2006- (22), circunstancia que supone, como ha señalado el Consejo de Estado, una mayor limitación con respecto a la normativa ante-

(19) Ya se preveía en la Ley 5/2006 - art. 6.2-. El Grupo Parlamentario Mixto en el Congreso, en la enmienda núm. 53, solicitaba la supresión del artículo 14.2, pues «debe ser totalmente incompatible tener participaciones en una sociedad que mantiene vinculación contractual con el ámbito público» (BOCD Serie A núm. 83-2, 9 de diciembre de 2014).

(20) En un mismo sentido el articulo 4.3 Ley Comunitat Valenciana 8/2016 y 7.2.e) Ley Castilla y León $3 / 2016$.

(21) Véanse las reflexiones de J. MESEGUER YEBRA, Régimen de conflictos de intereses e incompatibilidades..., ob. cit., p. 118.

(22) Esta redacción, como ha señalado el Consejo de Estado, comporta una mayor limitación respecto de la prevista en el artículo 6 de la Ley 5/2006, que circunscribía la anterior limitación respecto de las subvenciones provenientes de la Administración General del Estado. Véase Dictamen del Consejo de Estado 1435/2013, de 6 de febrero de 2014, sobre el Anteproyecto de ley reguladora del ejercicio del alto cargo de la Administración General del Estado. 
rior (23)y (24). Sin embargo, no queda resuelto si esta limitación exige que el alto cargo por sí, o a través de persona interpuesta, tenga una participación del diez por cierto en la empresa que recibe la subvención o si por el contrario, no está sujeta a porcentaje alguno, resultando lo único relevante que la misma reciba subvenciones.

La solución es compleja en la medida que la redacción es desafortunada cuando dispone que: «Los altos cargos no podrán tener, por sí o por persona interpuesta, participaciones directas o indirectas superiores a un diez por ciento en empresas (...) o que reciban subvenciones provenientes de cualquier Administración Pública». Una primera aproximación parece conducirnos a la idea de que la percepción de subvenciones no va vinculada a porcentajes de participación al establecer una disyuntiva. Esta posible interpretación tendría como consecuencia una limitación estricta en la medida que cualquier participación, por pequeña que fuese, de un alto cargo en una empresa que recibiese subvenciones, estaría prohibida. La segunda opción sería entender qué es exigible para que se perfeccione la limitación de que el alto cargo tenga participaciones que sumen el porcentaje previsto y que la empresa reciba subvenciones. Esta segunda opción es la más razonable, pues de otra manera un alto cargo no podría tener ninguna participación en una empresa que recibiese subvenciones por parte de cualquier administración pública. Además sería conveniente establecer unos límites a las cantidades subvencionadas en la medida que las subvenciones son muy variadas y por importes muy distintos. De hecho, de lege ferenda podría establecerse una limitación absoluta en los casos de subvenciones otorgadas por la Administración General del Estado, ámbito directo de influencia del alto cargo, y en los demás casos establecer unos mínimos para que fuesen relevantes a estos efectos.

Por último, tampoco resulta de fácil comprensión la expresión empresas «que reciban subvenciones provenientes de cualquier Administración Pública", pues "que reciban" parece indicar que las citadas empresas son destinatarias "habituales" de este tipo de ayudas públicas y no se vincula a un momento concreto. Por tanto, en teoría sería suficiente que la empresa hubiese recibido subvenciones durante unos años anteriores al nombramiento del alto cargo. Esta solución no es satisfactoria y por ello, entendemos que debe interpretarse en un sentido restrictivo y abarcar

(23) Dictamen del Consejo de Estado 1435/2013, de 6 de febrero de 2014, sobre el Anteproyecto de ley reguladora del ejercicio del alto cargo de la Administración General del Estado.

(24) La Exposición de Motivos de la Ley 3/2015 considera esta medida un gran avance cuando manifiesta que: "Se refuerza también la regulación de las limitaciones en participaciones societarias en el sentido de que también será incompatible la participación en más de un diez por ciento en empresas que reciban subvenciones que provengan de cualquier Administración Pública». 
exclusivamente el tiempo en el que el alto cargo está en activo o, como mínimo, establecer un plazo. Con todo, es importante tener presente que la concesión de una subvención puede conllevar un plazo muy amplio de ejecución y de posterior justificación. En ese interin, uno de los participantes de la empresa podría ser nombrado alto cargo. En estos casos, entiendo que el alto cargo debería, si tiene más del diez por ciento, enajenar o ceder los excedentes, inhibirse en los casos en que por razón de su cargo tenga alguna competencia sobre la gestión de la subvención y comunicarlo a la Oficina de Conflictos.

\section{C) PARTicipación EN UNA EMPRESA SubCONTRATISTA DE OtRA QUE TENGA CONTRATOS DE CUALOUIER NATURALEZA CON EL SECTOR PÚBLICO}

La Ley 3/2015, como ya se contemplaba en la Ley 5/2006 - art. 6.1 - (25), extiende la limitación a los supuestos en los que la vinculación del alto cargo no sea directamente con la empresa que contrata la Administración Pública, sino con la que subcontrata. Una medida que debe ser siempre calificada, a priori, de acertada en la medida que evita o limita el fraude de ley pues sin ella sería sencillo burlar la limitación impuesta a través de mecanismos de ingeniería empresarial.

Así, el artículo 14.1 manifiesta que «lo dispuesto en el párrafo anterior será también de aplicación al caso en que la empresa en la que participen sea subcontratista de otra que tenga contratos de cualquier naturaleza

(25) En la Ley 12/1995 la subcontratación no se recogía, y por tanto, pese a que algunas interpretaciones parecían indicar que en la expresión «participaciones superiores a un diez por ciento en empresas que tengan conciertos o contratos, de cualquier naturaleza, con el sector público estatal, autonómico o local» (art. 2.1) podía entenderse que también afectaba a la subcontratación. De hecho, incluso durante la tramitación Parlamentaria de la Ley Galicia 9/1996, con una redacción idéntica (art. 3.4) se propugnó una que pretendía extender su dicción al ejercicio de cargos directivos y de gestión en empresas subcontratistas, tesis que, en definitiva no prosperó, por entenderse insertada, implícitamente en los supuestos de la ley (Boletín Oficial del Parlamento de Galicia, de 26 de agosto de 1996, p. 13.851). Sin embargo, las dudas en este sentido eras múltiples pues como se manifestó en el Dictamen 121/2001, de 8 de junio, del Consejo Consultivo de Galicia «con la expresión conciertos o contratos exigen inequívocamente, como presupuesto, el convenio directo con la Administración Pública, cosa que no ocurre con los subcontratos, según explicita el artículo 115.3 del vigente texto refundido de la LCAP y así entiende unánime y reiteradamente la jurisprudencia, doctrina jurisprudencial que actualmente viene corroborada por el artículo 11 del vigente texto refundido cuando entre los requisitos de los contratos de las administraciones menciona, entre otros que aquí no nos interesan, la presencia de un contratista y como condición sine qua non, la concurrencia en la relación negocial de una Administración; requisito que no se da en el subcontrato, precisamente, porque la única relación que en el subcontrato se establece es entre el contratista y el subcontratista. La conclusión que se impone, por lo dicho, sobre el primer punto del dictamen es que el subcontrato no está tipificado como causa de incompatibilidad en el artículo 3.4 de la Ley gallega 9/1996, de 18 de octubre, siempre que concurran las circunstancia que el precepto prevé, y concretamente que el alto cargo no ostente cargo directivo en la empresa subcontratada". Véase las interesantes reflexiones sobre la materia de J. MESEGUER YEBRA, Régimen de conflicto de intereses..., ob. cit., pp. 123 y ss. 
con el sector público estatal, autonómico o local siempre que la subcontratación se haya producido con el adjudicatario del contrato con la Administración en el que el alto cargo preste servicios y en relación con el objeto del contrato".

La redacción, muy mejorable, plantea dudas e incógnitas que comienzan con la referencia "a lo dispuesto en el párrafo anterior», pues el párrafo anterior se refiere a las personas interpuestas cuando considera «persona interpuesta a la persona física o jurídica que actúa por cuenta del alto cargo". De este modo, no se alcanza, en una interpretación literal, a entender el sentido del precepto en la medida en que simplemente se define la figura de la persona interpuesta, pero realmente ello no da sentido al texto. Por tanto, entiendo que el precepto realmente se refiere al primer párrafo del artículo 14.1, esto es «los altos cargos no podrán tener, por sí o por persona interpuesta, participaciones directas o indirectas superiores a un diez por ciento..." (26)y (27).

Por ello, partiendo de esta premisa, el precepto extiende la prohibición de participar a los altos cargos con más de un diez por ciento, directamente o a través de persona interpuesta, en una empresa que subcontrate con otra que tenga contratos de cualquier naturaleza con el sector público.

La Ley ha establecido un requisito, esto es que "la subcontratación se haya producido con el adjudicatario del contrato con la Administración en la que el alto cargo preste servicios y en relación con el objeto de ese contrato". Este requisito conlleva o produce una diferencia con respecto a la regla general en cuanto que se exige que el adjudicatario del contrato lo sea con la Administración donde el alto cargo desarrolla o desempeña su función y en relación a ese contrato. De este modo, la previsión del precepto no se aplicaría en caso de que la Administración que hubiese adjudicado el contrato fuese distinta a aquella en la que el alto cargo preste servicios como, por ejemplo, sucedería en el supuesto de que la Junta de Andalucía adjudicase un contrato a una empresa y esta última

(26) En apoyo de esta teoría el punto 31 de la Resolución de 28 de julio de 2005, de la Subsecretaría, por la que se da publicidad al Acuerdo del Consejo de Ministros, de 22 de julio de 2005, por el que se aprueban las Directrices de técnica normativa, que bajo la rúbrica División del artículo, dispone que: «El artículo se divide en apartados, que se numerarán con cardinales arábigos, en cifra, salvo que solo haya uno; en tal caso, no se numerará. Los distintos párrafos de un apartado no se considerarán subdivisiones de este, por lo que no irán numerados.».

(27) En la Ley 5/2006, de 10 de abril, de regulación de los conflictos de intereses de los miembros del Gobierno y de los Altos Cargos de la Administración General del Estado la redacción en este particular era mucho más clara cuando disponía que "Los titulares de los cargos .... no podrán tener (...), participaciones directas o indirectas superiores a un diez por ciento en empresas en tanto tengan conciertos o contratos de cualquier naturaleza, con el sector público estatal, autonómico o local, o sean subcontratistas de dichas empresas o que reciban subvenciones provenientes de la Administración General del Estado». 
subcontratara con la empresa en la que el alto cargo tiene participaciones, en cuyo caso no operarían los límites impuestos.

Esta previsión en relación a la subcontratación me parece muy oportuna. Sin embargo, sería igualmente conveniente extenderla de lege ferenda a los supuestos en los que una empresa recibiese subvenciones por parte de la Administración en la que el alto cargo prestase sus servicios y ésta contratase a la empresa en la que el alto cargo tiene participaciones (28).

\section{D) Regularización del alto CARgo en CUANTO AL CUMPLIMIENTO dE LAS LIMITACIONES EN PARTICIPACIONES SOCIETARIAS}

El artículo 13.3 de la Ley $3 / 2015$ se ocupa, siguiendo en gran medida el artículo 6.3 de la Ley $5 / 2006$, de los supuestos en los que un alto cargo posea las participaciones en empresas en el momento del nombramiento o de manera sobrevenida durante el desarrollo del cargo cuando dispone que "... la persona que sea nombrada para ocupar un alto cargo poseyera una participación en los términos a los que se refieren los apartados anteriores, tendrá que enajenar o ceder a un tercero independiente, entendiendo como tal a un sujeto en el que no concurren las circunstancias contempladas en el apartado 1, las participaciones y los derechos inherentes a las mismas durante el tiempo en que ejerza su cargo, en el plazo de tres meses, contados desde el día siguiente a su nombramiento. Si la participación se adquiriera por sucesión hereditaria u otro título gratuito durante el ejercicio del cargo, la enajenación o cesión tendría que producirse en el plazo de tres meses desde su adquisición".

Con carácter previo al análisis de esta cuestión es necesario precisar o delimitar a qué se refiere el precepto con la expresión «Cuando la persona que sea nombrada para ocupar un alto cargo poseyera una participación en los términos a los que se refieren los apartados anteriores". Esto es, si la medida prevista en el apartado 3 del artículo 14, se aplica a los altos cargos que tengan más de un diez por ciento de participaciones societarias, con la salvedad, ya mencionada, de las sociedades anónimas cuyo capital supere los 600.000 euros, en las cuales el alto cargo, sin llegar al diez por ciento, ese porcentaje le permita tener una posición en el capital social que pueda condicionar de forma relevante su actuación o,

(28) Pensemos en el caso en el que el Ministerio de Agricultura da una subvención a una empresa ganadera para comprar material para actualizar las instalaciones y esta comprara a la empresa en la que el alto cargo del citado ministerio tiene participaciones para suministrar el material o para efectuar las obras pertinentes. 
por el contrario, las medidas previstas que afectan a los altos cargos con un diez por cierto, pues los porcentajes superiores están prohibidos (29).

La respuesta es evidente. Las medidas articuladas se aplican a aqueIlos supuestos en los que los altos cargos en el momento del nombramiento o durante el desarrollo del puesto, tienen participaciones superiores al diez por ciento en empresas con los requisitos del artículo 14.1, pues hasta ese porcentaje no existe limitaciones. El problema se origina cuando el citado porcentaje se supera. La solución a esta cuestión en la Ley $5 / 2006$, de 10 de abril, de regulación de los conflictos de intereses de los miembros del Gobierno y de los Altos Cargos de la Administración General del Estado era radical. El alto cargo debía desprenderse de las mismas (30) - entendemos de todas aquellas que le hicieran superar el $10 \%$ - en el plazo de tres meses (31), contados desde el día siguiente a su

(29) La Ley País Vasco 1/2014 contempla una fórmula similar, con la diferencia de que no la limita a las Sociedades Anónimas, sino que la extiende a las Sociedades Mercantiles, cuando dispone que: "Cuando se trate de sociedades mercantiles cuyo capital social suscrito supere los 600.000 euros, o la cuantía que al efecto se fije en las leyes de presupuestos, la prohibición establecida en el apartado anterior se aplicará cuando los sujetos descritos reúnan participaciones que, aun no llegando al diez por ciento allí establecido, supongan una posición en el capital de la empresa que permita condicionar de forma relevante su actuación” - art. 22.2-.

(30) Desprenderse de las participaciones superiores al diez por ciento es la única medida prevista en las leyes autonómicas. Véanse entre otros arts. 17.3 Ley Cantabria 1/2008 -que emplea el verbo transmitir-, 4.2 Ley Canarias 3/1997; 43.3 Ley Galicia 1/2016; art. 3.2 Ley Navarra 19/1996; 33.2 Ley Extremadura 1/2014; 58.2 Ley La Rioja 8/2003, 22.3 Ley País Vasco 1/2014 o 14.2 y 3 Ley Comunitat Valenciana 8/2016. Otras Comunidades Autónomas exclusivamente prohíben superar el porcentaje pero no establecen el plazo para deshacerse del excedente, como por ejemplo, Ley Andalucía 3/2005; Ley 4/1995; Ley Cataluña 13/2005. En el caso de Ley Castilla y León 3/2016 se estable un régimen muy particular cuando dispone que «En el supuesto de incursión en causa sobrevenida de incompatibilidad, el alto cargo deberá comunicarlo de manera inmediata a la Inspección General de Servicios y optar por solicitar el cese o realizar, en el plazo de dos meses desde que se produjo dicha causa, las actuaciones necesarias para eliminar la incompatibilidad. Si no se efectuara la opción expresa, se entenderá que opta por el cese y se procederá a su formalización».

(31) Las Comunidades Autónomas han previsto unos plazos muy variados, así, p. e., el art. 4.2 Ley Canarias 3/1997 prevé la posibilidad de que los plazos se amplíen en los supuestos en que por imperativo legal o por disposición estatutaria fuere preceptivo un plazo superior en el procedimiento de transmisión-; el art. 4.2 Ley Baleares 2/1996 y 343.4 Ley Galicia 1/2016 que establecen un plazo de un mes para deshacerse de las participaciones que se posean en el momento del nombramiento, plazo que se amplía a tres cuando se adquiera por sucesión hereditaria; el art. 3.2 Ley Navarra 19/1996 que dispone un plazo de dos meses a contar desde el día siguiente a su nombramiento y si la participación se adquiriese por sucesión hereditaria durante el ejercicio del cargo, tendrá que desprenderse de la misma en el plazo de cuatro meses desde su adquisición; el art. 33.2 Ley Extremadura 1/2014 prevé un plazo de un mes desde el nombramiento y de tres meses cuando lo sea por sucesión hereditaria y el art. 58.3 de La Ley La Rioja 8/2003 prevé un plazo general de dos meses y cuando sea por sucesión hereditaria de tres, y el art. 22.3 Ley País Vasco 1/2014 recoge un plazo para desprenderse de las participaciones que superen el límite del $10 \%$ en el plazo de los tres meses posteriores a su nombramiento. Si la situación patrimonial prohibida se adquiriera de manera sobrevenida durante el ejercicio del cargo, por sucesión hereditaria u otro título gratuito, tendrá igualmente tres meses, contados desde que se produzca la adquisición, para desprenderse de las participaciones que superen los límites establecidos o el art. 14.2 y 3 Ley Comunitat Valenciana 8/2016 que prevé dos meses tanto cuando es previa al nombramiento como cuando es sobrevenida, un plazo que comienza su cómputo en el momento de la notificación de la incompatibilidad. 
nombramiento y en el caso de que fuesen adquiridas por vía hereditaria u otro título gratuito durante su ejercicio, debía hacer lo mismo en el mismo plazo, teniendo como punto de partida el momento de la adquisición - art. 6.3-(32).

Esta solución, que hemos calificado de radical, obligaba al alto cargo a deshacerse de las participaciones de las que disponía, con independencia de la oportunidad efectuar la enajenación o transmisión, recordando que con la ley anterior no podía expresamente transferirse al cónyuge, sea cual fuere el régimen económico matrimonial, o la persona con la que conviviese en análoga relación de afectividad e hijos dependientes y personas tuteladas, mientras que ahora, como hemos analizado, la Ley 3/2015 se refiere a persona interpuesta exclusivamente. Este hecho podía comportar, por tanto, pérdidas patrimoniales significativas en la persona del alto cargo y entorpecer su regreso al ámbito profesional tras el cese.

La Ley 3/2015 ha subsanado esta situación en la medida que ha previsto la alternativa entre la enajenación o la cesión a un tercero independiente del ejercicio de los derechos correspondientes a las participaciones $(33)^{y}(34)$. Esta alternativa, valorada positivamente por el Consejo de Estado en el Dictamen al anteproyecto de ley, comporta la posibilidad de conservar la titularidad de las participaciones no obstante el ejercicio de

(32) P. GARCÍA MEXÍA - Los conflictos de intereses..., ob. cit., p. 155- consideraba muy positivo el carácter perentorio de los plazos para desprenderse de las participaciones.

(33) El Consejo de Estado consideró necesario que se especificara en la Ley "qué debe o puede entenderse por "tercero independiente» a los efectos del referido precepto, pues la mayor o menor consecución del objetivo de transparencia, legalidad y ausencia de conflictos que se proponen al anteproyecto se propone deriva, entre otros extremos, de la definición de conceptos jurídicos si no indeterminados, sí imprecisos, cuya delimitación corresponde a una norma del rango de la proyectada». Este motivo propició que se definiese en el mismo precepto, como un sujeto en el que no concurren las circunstancias contempladas en el apartado 1 ». Esto es, que no se trate de una persona interpuesta. Véase Dictamen del Consejo de Estado 1435/2013, de 6 de febrero de 2014, sobre el Anteproyecto de Ley reguladora del ejercicio del alto cargo de la Administración General del Estado.

(34) Un caso excepcional, en el marco autonómico que sigue el ejemplo de la Ley $5 / 2006$, esto es la obligación del alto cargo de "desprenderse" de las participaciones que superen el $10 \%$, el que se encuentra en el artículo 17 de la Ley Cantabria 1/2008, que opta por una fórmula mucho más rígida que la articulada en la Ley $3 / 2015$. Así se parte de la premisa de que los altos cargos no podrán administrar personalmente las participaciones que posean por sí o junto con su cónyuge o persona que conviva en análoga relación de afectividad e hijos dependientes y personas tuteladas, en empresas o sociedades que tengan conciertos o contratos de cualquier naturaleza con el sector público autonómico. Por tanto, con independencia del porcentaje de participación se le prohíbe la administración personal de las mismas para lo cual y dentro del plazo de tres meses desde que tuviera lugar el nombramiento o la adquisición de las participaciones, las personas que se encuentren bajo el ámbito de aplicación de la presente Ley deberán encomendar la administración de las participaciones a sociedades especializadas mientras dure el ejercicio del cargo, debiendo ser inscrito el contrato de encomienda en el Registro de Bienes y Derechos Patrimoniales en la forma que reglamentariamente se determine. Sin embargo, esto no es todo, pues en los supuestos en que las participaciones sean superiores al diez por ciento del capital social de dichas empresas o sociedades, se les obliga en el plazo de tres meses desde el nombramiento a proceder a su transmisión, hasta quedar incluidas en este límite. 
los derechos asociados a las mismas corresponderá a un tercero independiente (35)y (36).

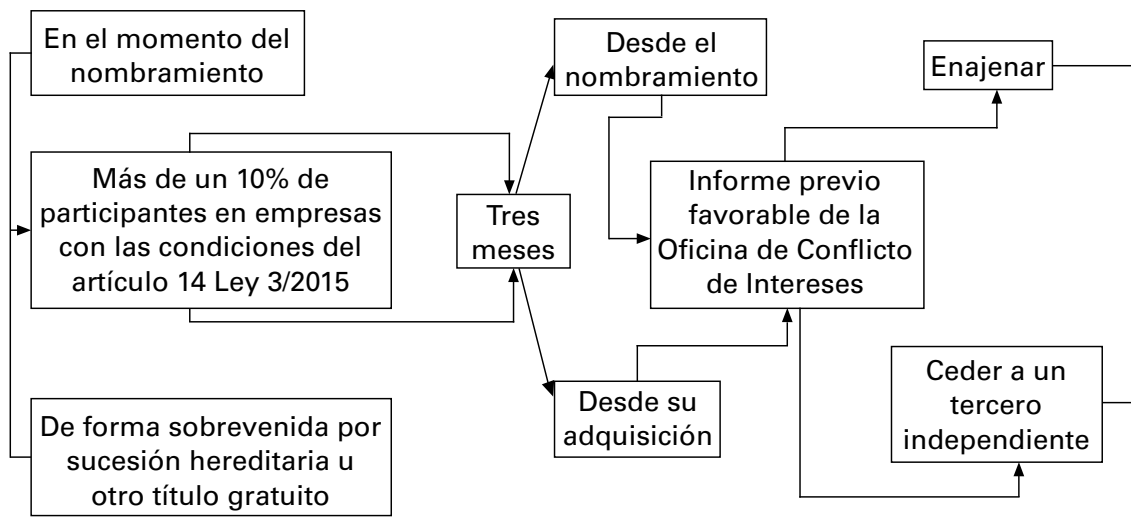

Declaración al Registro de Actividad y de Bienes y Derechos Patrimoniales

La obligación de enajenar o ceder las participaciones y los derechos inherentes a las mismas tiene una serie de controles, traducidas en las obligaciones de:

a) Disponer de un informe favorable y previo a la operación de enajenación o cesión de la Oficina de Conflictos de Intereses. En el momento en que se solicita el mismo por parte del alto cargo, se debe entender suspendido el plazo de tres meses para la enajenación o cesión hasta que se reciba el informe. Con todo, entendemos que hubiera sido más oportuno que se estableciera la obligación inmediata de solicitud del informe en el momento en que el alto cargo es nombrado o cuando de forma sobrevenida supera el límite de

(35) El Consejo de Estado recomendaba «modificar la redacción del apartado señalado para especificar que, si eso es lo que se pretende, se aclare que los derechos cuya cesión puede articularse a favor de un tercero, son los derechos políticos, pero no los derechos económicos en la medida en la que no resulten contrarios a las restantes previsiones contenidas en la Ley proyectada». Véase Dictamen del Consejo de Estado 1435/2013, de 6 de febrero de 2014, sobre el Anteproyecto de ley reguladora del ejercicio del alto cargo de la Administración General del Estado.

(36) Debemos apreciar que la Ley 5/2006 empleaba el verbo desprenderse, que comporta cualquier acción que permita eliminar del patrimonio del alto cargo las citadas participaciones, entre las que se encuentra la enajenación y también la donación, pero la Ley 3/2015 exclusivamente recoge como medidas posibles la enajenación o la cesión. 
participaciones previsto, y sólo a partir de la recepción del informe, comenzase el cómputo del tiempo para la enajenación o cesión.

b) Declarar las operaciones, así como la identificación, en su caso, del tercero independiente a los Registros de Actividades y de Bienes y Derechos Patrimoniales(37). No existe un plazo para declarar las comunicaciones $y$, por ello, debemos acudir al plazo general de tres meses previsto en el artículo 17 de la Ley 3/2015 para la declaración de bienes y derechos.

\section{Cuadro resumen}

\begin{tabular}{|c|c|c|c|}
\hline $\begin{array}{l}\text { Requisitos } \\
\text { del alto cargo }\end{array}$ & Requisitos de las empresas & \multicolumn{2}{|c|}{ Consecuencias } \\
\hline \multirow{4}{*}{$\begin{array}{l}\text { Más de } 10 \% \text {, por sí } \\
\text { o por persona inter- } \\
\text { puesta, participacio- } \\
\text { nes directas o indi- } \\
\text { rectas en empresas. } \\
\text { Excepción aunque el } \\
\text { porcentaje sea me- } \\
\text { nos del 10\%: socieda- } \\
\text { des anónimas cuyo } \\
\text { capital social suscrito } \\
\text { supere los } 600.000 \\
\text { euros, y las participa- } \\
\text { ciones del alto cargo, } \\
\text { aun siendo inferiores } \\
\text { al porcentaje, le otor- } \\
\text { guen una posición en } \\
\text { el capital social que } \\
\text { pueda condicionar de } \\
\text { forma relevante su ac- } \\
\text { tuación. }\end{array}$} & \multirow{4}{*}{$\begin{array}{l}\text { - Tenga conciertos o } \\
\text { contratos de cualquier } \\
\text { naturaleza con el sec- } \\
\text { tor público estatal, au- } \\
\text { tonómico o local. } \\
\text { - Reciba subvenciones } \\
\text { de cualquier Adminis- } \\
\text { tración Pública. } \\
\text { - La empresa en la que } \\
\text { participe sea subcon- } \\
\text { tratista de otra que ten- } \\
\text { ga contratos de cual- } \\
\text { quier naturaleza con } \\
\text { el sector público esta- } \\
\text { tal, autonómico o local } \\
\text { siempre que la subcon- } \\
\text { tratación se haya pro- } \\
\text { ducido con el adjudica- } \\
\text { tario del contrato con } \\
\text { la Administración en la } \\
\text { que el alto cargo preste } \\
\text { servicios y en relación } \\
\text { con ese contrato. }\end{array}$} & $\begin{array}{l}\text { Obligación alter- } \\
\text { nativa de: }\end{array}$ & Plazo: \\
\hline & & $\begin{array}{l}\text { Enajenar o Ce- } \\
\text { der a un tercero } \\
\text { independiente, } \\
\text { el excedente su- } \\
\text { perior al } 10 \% .\end{array}$ & $\begin{array}{l}\text { Tres meses desde } \\
\text { el nombramiento } \\
\text { o desde la adquisi- } \\
\text { ción por sucesión } \\
\text { hereditaria u otro } \\
\text { título gratuito. }\end{array}$ \\
\hline & & \multicolumn{2}{|c|}{ Garantías } \\
\hline & & \multicolumn{2}{|c|}{$\begin{array}{l}\text {-Disponer de un informe favorable } \\
\text { y previo a la operación de enaje- } \\
\text { nación o cesión de la Oficina de } \\
\text { Conflictos de Intereses. } \\
\text {-Declarar las operaciones, así como } \\
\text { la comunicación, en su caso, del } \\
\text { tercero independiente a los Regis- } \\
\text { tros de Actividades y de Bienes y } \\
\text { Derechos Patrimoniales. }\end{array}$} \\
\hline
\end{tabular}

(37) Esta exigencia ya se recogía en el artículo 3.2 Ley 12/1995 y, posteriormente, en el artículo 6.3 de la Ley $5 / 2006$. 


\section{Control y gestión de valores y activos financieros}

El artículo 18 de la Ley 3/2015, Control y gestión de valores y activos financieros(38), tiene su antecedente en el artículo 7 de la Ley la Ley 12/1995, de 11 de mayo, de incompatibilidades de los miembros del Gobierno de la Nación y de los Altos Cargos de la Administración General del Estado, que con alguna modificación se incorporó, con la misma rúbrica en el artículo 13 de la Ley 5/2006. Es una figura que, como han dejado de manifiesto distintos autores, es conocida como fideicomiso ciego, fondo ciego o administración dormida, y que goza de un amplio arraigo en la legislación estadunidense(39). El fideicomiso ciego permite a una persona que ejerce un alto cargo, ceder la administración de su patrimonio a un tercero independiente, originándose un virtual muro entre una autoridad pública y su patrimonio, todo ello con el fin de evitar cualquier conflicto de intereses en las decisiones que debe adoptar en el ejercicio de su cargo (40).

(38) La rúbrica de este precepto no ha cambiado con respecto a las dos leyes anteriores. Sin embargo, en el anteproyecto la rúbrica del artículo 18 era "Control y gestión de acciones y participaciones societarias». Fue el Consejo de Estado el que sugirió modificar la rúbrica del artículo y mantener la denominación actual, que era la contenida en el artículo 13 de la Ley 5/2006, "Control y gestión de valores y activos financieros", "y ello porque carece de sentido prever la contratación con una entidad financiera registrada en la CNMV para la gestión y administración de acciones (si lo son de sociedades no cotizadas) y participaciones en sociedades de responsabilidad limitada». De esta manera, argumentaba el Organo Consultivo que "no puede perderse de vista que la Ley 24/1988, de 28 de julio, del Mercado de Valores y, en el mismo sentido, la Comisión Nacional del Mercado de Valores operan en el marco de los mercados de instrumentos financieros cotizados o cuyo subyacente cotice, por lo que aquélla carece de competencias sobre las acciones y participaciones de empresas no cotizadas. $Y$, por tanto, "Si lo que se pretende es asegurar que la gestión de acciones y participaciones sociales por el alto cargo no incurra en ningún riesgo de conflicto de interés con el cargo público que ostenta, tal fin se alcanza mediante la enajenación o cesión de los derechos políticos derivados de unas y otras - circunstancia que prevé el artículo $14 \mathrm{del}$ anteproyecto-. En cambio, si lo que se propone el artículo 18, como parece deducirse de la redacción propuesta y de la equivalente actualmente vigente, es asegurar que el alto cargo no pueda incidir de ningún modo en las decisiones de inversión relativas a su cartera de activos durante el tiempo que ostenta el alto cargo, basta con su regulación en los términos previstos, si bien especificando que se trata de valores e instrumentos financieros". Como consecuencia "y para adaptar la denominación del precepto a la regulación vigente en materia de Mercado de Valores, debería sustituirse la expresión activos financieros por la de valores e instrumentos financieros, que es la contenida en el artículo 2 de la Ley 24/1988, de 28 de julio, del Mercado de Valores». Dictamen del Consejo de Estado 1435/2013, de 6 de febrero de 2014, sobre el Anteproyecto de ley reguladora del ejercicio del alto cargo de la Administración General del Estado.

(39) J. MESEGUER YEBRA, Régimen de conflictos de intereses e incompatibilidades..., ob. cit., p. 243 y P. GARCÍA MEXÍA, Los conflictos de intereses y la corrupción contemporánea, Arazandi, 2001, p. 215.

(40) Véanse las consideraciones de A. CERRILLO I MARTÍNEZ, "Los conflictos de intereses y los actos de integridad: la prevención de la corrupción en los contratos públicos», en AA.VV., La corrupción en España, Atelier, Barcelona, 2016, pp. 196-197. 


\section{A) Ámbito subjetıvo}

El control y gestión de valores y activos financieros ha sufrido un proceso de ampliación de su ámbito subjetivo. Así, en la Ley 12/1995 esta figura estaba prevista exclusivamente para los altos cargos que ostentasen competencias reguladoras, de supervisión o control sobre sociedades mercantiles, cuando emitiesen valores y otros activos financieros negociables en un mercado organizado $y$, en relación con aquéllos de que fuesen titulares tales personas, sus cónyuges no separados legalmente o sus hijos menores de edad no emancipados. Esta línea fue seguida por la Ley $5 / 2006$ que, sin embargo, la extendió también a los miembros del Gobierno y Secretarios de Estado, manteniendo la previsión en relación a los hijos y los cónyuges. Sin embargo, estos últimos quedaban excluidos cuando el régimen matrimonial fuese el de separación de bienes. Como final de este proceso, la Ley $3 / 2015$ ha extendido la figura a todos los altos cargos sin distinción pero, sin embargo, se han eliminado las referencias a los hijos y cónyuges(41), como también, se ha producido, como hemos analizado en el caso de las limitaciones patrimoniales en participaciones societarias - art. 14- o en el caso, de las declaraciones voluntarias de bienes y derechos.

\section{B) ConTENIDO MATERIAL}

Los altos cargos deben contratar, conforme con las previsiones del Real Decreto Legislativo 4/2015 de 23 de octubre, por el que se aprueba el texto refundido de la Ley del Mercado de Valores (42), a una empresa autorizada a prestar servicios de inversión para la gestión y administración de las acciones $u$ obligaciones admitidas a negociación en mercados regulados o en sistemas multilaterales de negociación, productos derivados sobre las anteriores, acciones de sociedades que hayan anunciado su decisión de solicitar la admisión a negociación y participaciones en instituciones de inversión colectiva, siempre y cuando no se dé ninguna de

(41) La normas autonómicas siguen incluyendo a los cónyuges e hijos menores no emancipados: véanse los artículos 23.1 Ley País Vasco 1/2014; 11.1 Ley Canarias 3/1997; 15.1 Ley Cataluña 13/2005; 15.1 Ley Navarra 19/1996 - art. 13.1 - o 59.1 Ley La Rioja 8/2003.

(42) En el Anteproyecto de Ley no se especificaba que el contrato se debía realizar de conformidad a la ley 24/1988, y fue el Consejo de Estado en el Dictamen del Consejo de Estado 1435/2013, de 6 de febrero de 2014, sobre el Anteproyecto de Ley reguladora del ejercicio del alto cargo de la Administración General del Estado, el que señaló la necesidad de que los mismos se realizasen conforme a la Ley 24/1988 - esta referencia debe entenderse ahora realizada al Real Decreto Legislativo 4/2015 de 23 de octubre, por el que se aprueba el texto refundido de la Ley del Mercado de Valores - "para asegurar la realización del oportuno test de idoneidad donde se recojan los criterios de inversión y de riesgo de la persona afectada». 
las excepciones descritas en el epígrafe siguiente. Esta contratación se mantendrá exclusivamente mientras dure el desempeño del alto cargo y, por tanto, no se aplicará el régimen común de los dos años previsto para todas las actividades de los ex-altos cargos y que preveía expresamente la Ley $12 / 1995$ (43).

Por su parte, la entidad con la que el alto cargo contrate la gestión de sus valores y activos financieros realizará su actividad, sin que pueda recabar ni recibir instrucciones de inversión de los interesados, siguiendo exclusivamente las directrices generales de rentabilidad y riesgo establecidos en el contrato (44). La norma prevé consecuencias importantes para las entidades cuando el artículo 18.3 in fine dispone que el incumplimiento de la entidad de las obligaciones previstas tendrá la consideración de infracción muy grave a los efectos del régimen sancionador que como entidad financiera le fuese aplicable (45).

La Ley impone a los altos cargos la obligación de entregar las copias de los contratos suscritos a la Oficina de Conflictos de Intereses para su anotación en los Registros(46), así como a la Comisión Nacional del Mer-

(43) MESEGUER YEBRA - Régimen de conflictos de intereses e incompatibilidades..., ob. cit., p. $244-$ entiende que "el establecimiento de plazos sería necesario para evitar que la información privilegiada adquirida durante el ejercicio del cargo público pueda ser utilizada perniciosa e interesadamente en provecho propio». La Ley Cataluña 13/2015 prevé que "La gestión a cargo de esta entidad debe mantenerse mientras ejerzan el cargo y los dos años posteriores al cese» - art. 15.1-.

(44) En el artículo 18.2 del Anteproyecto de Ley se disponía «que tampoco podrá revelárseles la composición de sus inversiones - a los altos cargos titulares de los valores e instrumentos financieros gestionados a través de la entidad financiera-, salvo que se trate de instituciones de inversión colectiva o que, por causa justificada, medie autorización de la Comisión Nacional del Mercado de Valores", cuestión que fue retirada como conciencia del Dictamen del Consejo de Estado 1435/2013, de 6 de febrero de 2014, sobre el Anteproyecto de Ley reguladora del ejercicio del alto cargo de la Administración General del Estado, pues como manifestó el Órgano Consultivo «Esta previsión carece de conexión con la realidad en la medida en la que el alto cargo deberá conocer de sus inversiones - aunque no las gestione ni pueda decidir sobre ellas - aunque sólo sea para la formulación de su declaración anual del Impuesto del Patrimonio o del Impuesto de la Renta de las Personas Físicas, cuya aportación anual exige el artículo 17.2 del anteproyecto, o para poder disponer o decidir acerca de la gestión que se realice de sus inversiones. Parece que la prohibición de incidir sobre las decisiones que el gestor adopte respecto de las inversiones del alto cargo no es incompatible con la facultad de éste de valorar la gestión de su cartera y optar por un contrato con una entidad o gestor distinto, a la vista del resultado de su actuación». En el mismo sentido, véanse por ejemplo, los artículos 15.1 Ley Cataluña 13/20005; 23.2 Ley País Vasco 1/2014; 59.2 Ley La Rioja 8/2003; 13.1 Ley Navarra 19/1996 o 11.2 Ley Canarias 3/1997.

(45) Esta es una consecuencia que ya se preveía en los artículos 7.1 in fine de la Ley 12/1995 y 13.1 in fine de la Ley 5/2006. También se encuentra algún ejemplo en la normativa autonómica, como el artículo 13.1 in fine de la Ley Navarra 19/1996.

(46) Las regulaciones autonómicas han previsto la obligación de entregar copia del contrato de gestión y administración suscrito con entidad financiera en el registro de bienes patrimoniales, en el caso de la Ley Cataluña 13/2005, para que sean anotados en la Comisión Nacional del Mercado de Valores - art. 15.2-, o exclusivamente al Registro, como es el caso, entre otros, de la Ley Canarias 3/1997 - art. 11.3 - , Ley País Vasco 1/2014 - art. 23.1 - o Ley La Rioja 8/2003 - art. 59.3- o tanto al Registro de Actividades e intereses y a la Comisión Nacional del Mercado de Valores, como por ejemplo, la Ley Navarra 19/1996 - art. 13.2-. 
cado de Valores (47). La Ley no especifica ni el plazo para la formulación de los contratos ni para la entrega de la copia de los mismos a la Oficina de Conflictos y a la Comisión Nacional del Mercado de Valores (48). En ese sentido, entendemos que el contrato debería suscribirse incluso antes de la toma de posesión y ser remitido a las entidades inmediatamente, no sobrepasando en ningún caso el plazo de tres meses previsto para declaraciones de bienes y derechos.

\section{C) EXCEPCIONES}

La obligación de contratar una empresa autorizada para la gestión de los valores y activos financieros de los altos cargos tiene dos excepciones. Una primera de naturaleza cuantitativa de los citados valores y activos que se fija en 100.000 euros (49), cantidad que se calculará por el valor a los efectos del Impuesto sobre Patrimonio (50).

La segunda excepción es de naturaleza cualitativa - sin precedentes en la legislación anterior - esto es, no se aplicará el régimen previsto cuando los valores o activos financieros de que sea titular el alto cargo sean participaciones en instituciones de inversión colectiva en los que no se tenga una posición mayoritaria o cuando, tratándose de valores de entidades distintas, el alto cargo no realice ningún acto de disposición por iniciativa propia y tan sólo se limite a percibir los dividendos, intereses o retribuciones en especie equivalentes, acudir a ofertas de canje, conversión o públicas de adquisición.

(47) Esta previsión ya se contenía en el artículo 13.2 de la Ley 5/2006. La Ley 12/1995 establecía la obligación de entregar copias de los contratos a la Comisión Nacional del Mercado de Valores, pero no hacía referencia a la Oficina de Conflicto de Intereses pues su creación se produjo con la Ley $5 / 2006$, y exigía entregar los contratos en el Registro de Bienes y Derechos Patrimoniales.

(48) La Ley Canarias 3/1997 ha previsto que "Los altos cargos que se encuentren en la situación descrita en el apartado 1 de este artículo remitirán, dentro del mes siguiente a su celebración, copia del contrato suscrito con la entidad financiera al Registro de Intereses de Altos Cargos" - art. $11.3-$.

(49) En la Ley País Vasco 1/2014 se ha contemplado la misma cantidad de 100.000 euros, pero se diferencia en el hecho de que será calculada según su cotización media correspondiente al trimestre anterior a la toma de posesión-art. 23.1 in fine-.

(50) Esta cantidad era la que se preveía tanto en la Ley 12/1995 - art. 7.1 - como en la Ley 5/2006 -art. 13-. Sin embargo, recordemos que estas leyes incluían a los efectos del cómputo a los hijos menores no emancipados y a los cónyuges no separados legalmente, siempre que no fuese en régimen de separación de bienes. 


\section{Producción y creación literaria, artística, científica o técnica y las publicaciones derivadas de aquéllas}

Esta actividad privada compatible, con idéntica redacción, en las Leyes $12 / 1995$ y $5 / 2006$, tiene dos límites: a) no pueden ser consecuencia de una relación de empleo o de prestación de servicios y $b$ ) no puede suponer un menoscabo del estricto cumplimiento de sus deberes, y dos perspectivas: por una parte, la creación o producción de obras artísticas o intelectuales y por otra parte, la publicación de aquellas (51).

La creatividad es una manifestación del principio de libertad de expresión, un medio de desarrollo de la personalidad y un derecho reconocido en el artículo 20.1.b) de la Constitución que contempla el derecho a la "producción y creación literaria, artística, científica y técnica" que en modo alguno puede ser cercenado por ninguna norma de incompatibilidad. Todo ello sin olvidar la imposibilidad real de impedir a un alto cargo, esto es una persona, que manifieste su creatividad o desarrolle su inquietud intelectual en su vida estrictamente privada. Sin embargo, ello no es obstáculo para que se establezca la limitación o la salvedad que introduce el precepto que exige que estas actividades no se desarrollen en el marco de una relación de empleo, pues afectaría al principio de dedicación exclusiva, o que suponga un menoscabo del estricto cumplimiento de sus funciones, que atentaría frontalmente con uno de los elementos teleológicos del principio anterior, que es lograr que el alto cargo no se vea afectado por otras actividades que limiten su capacidad para el desempeño de sus cometidos (52).

(51) Véanse también, entre otros, los artículos 7.2.a) Ley Castilla y León $3 / 2016$, 7.1.c) Ley Comunitat Valenciana 8/2016; 8.1.b) Ley Canarias 3/1997; 8.1.d) Ley Cataluña 13/2005; 11.b) Ley Cantabria 1/2008; 56.b) Ley La Rioja 8/2003; 2.1.b) Ley Galicia 1/2016 y 6 Ley Navarra 19/1996.

(52) En este sentido, el Tribunal Constitucional, en su Sentencia de 2 de noviembre de 1989 (RTC 1989 178), analiza la posible inconstitucionalidad de la limitación - va referida a la Ley estatal de 1984 pero el contenido es el mismo que el de la Ley Andalucía 3/2005- al considerar los recurrentes que la salvedad establecida condicionaba el ejercicio de la libertad de expresión. El Alto Tribunal manifestó que «no hay tal condicionamiento, sin embargo, si se tiene en cuenta la finalidad que persigue el precepto, que es, precisamente, excluir del régimen de incompatibilidades - con todas sus consecuencias, incluidas, claro es, las de naturaleza económica- la producción y creación literaria, artística, científica y técnica. Que se haga la salvedad de la producción realizada como consecuencia de una relación de empleo o de prestación de servicios para nada afecta a dicha libertad, sino exclusivamente a la titularidad de la referida producción, que, por recaer en el ente público de que se trate, no tiene ningún sentido que se exceptúe ese supuesto del régimen de incompatibilidades. Los demandantes reprochan también la limitación del carácter ocasional, contenida en los apartados g) y h) del repetido precepto, que consideran que infringe, simultáneamente, los arts. 20 y 27 de la Constitución. Sin embargo, la limitación en cuestión es perfectamente razonable y coherente con el sistema de incompatibilidades establecido en la Ley 53/1984, ya que de no existir esa limitación, "el ejercicio habitual, reiterado y constante de las actividades a que se refieren los apartados g) y h) del art. 19 de la Ley impugnada podría entrar en contradicción con la dedicación al puesto de trabajo en la Administración, con menoscabo de la eficacia de la actividad del correspondiente ente público» (F. J. undécimo).). 
En cuanto a la publicación, concepto que debe entenderse en un sentido amplio y finalista, pues existen creaciones que no se publican como, por ejemplo, esculturas o pinturas, sigue el mismo criterio (53). Esto es, se podrá "publicar», que es la forma de comercializar la obra, siempre que no sea consecuencia de una relación de empleo con la editorial, con la galería... En este sentido, hubiera resultado oportuno, y por ello, lo proponemos de lege ferenda, introducir el elemento de no habitualidad, como hace por ejemplo el artículo 4.2.a) del Decreto Andalucía 176/2005 cuando dispone que «... así como las publicaciones derivadas de aquéllas podrán efectuarse de forma no habitual y siempre que no sean consecuencia de una relación de empleo o prestación de servicios".

Por último, existe un tema interesante relacionado con esta cuestión que se concreta en dilucidar si los altos cargos en ejercicio de esta actividad compatible podrían recibir los emolumentos correspondientes.

Una respuesta apresurada, tras la lectura del artículo 13.1 in fine de la Ley $3 / 2015$ - «tampoco podrán percibir cualquier otra remuneración con cargo a los presupuestos de las Administraciones Públicas o entidades vinculadas o dependientes de ellas, ni cualquier otra percepción que, directa o indirectamente, provenga de una actividad privada simultánea»podría inclinarnos a pensar que sería incompatible cualquier retribución por el desarrollo de las citadas actividades.

Sin embargo, el punto segundo del citado artículo comienza manifestando "lo dispuesto apartado anterior se entiende sin perjuicio de las excepciones siguientes", entre las que se encuentra esta, y, por tanto, entendiendo que no existe ningún problema que se derive de la norma para que pudiera percibir las retribuciones fijadas o acordadas. Esta solución, ajustada a Derecho, no resulta absolutamente satisfactoria en la medida en que se pueden producir situaciones alejadas del espíritu de la Ley, como, por ejemplo, que se le encargarse un informe a un alto

(53) La Ley País Vasco 1/2014 ha individualizado como causa compatible "La comercialización y publicación de producción y creación literaria, artística, científica o técnica, siempre que no traigan causa de una relación de trabajo o de un contrato de prestación de servicios" - art. 14.1.c) - y no prevé las "de producción y creación literaria, artística, científica o técnica». Esta opción puede tener sentido en la medida que la actividad creativa, en términos generales, no es susceptible de limitación pues se halla dentro de la esfera privada de cada individuo, aún en los supuestos en que afectara o supusiera un menoscabo del cumplimiento, siempre que se desarrolle al margen de una relación de empleo o prestación de servicios. Sin embargo, la comercialización y publicación, se producen en un momento posterior al de la "creación" y podría afectar a la independencia e imparcialidad. Con todo, y aunque la anterior afirmación es generalmente cierta, pueden darse supuestos en los que la creación, pese a ser un acto personalísimo, puede realizarse como consecuencia de una relación de empleo en cuyo caso podría generar problemas de compatibilidad. 
cargo, que fuese pagado con dinero público, aunque el mismo se lo hubiera encomendado la Administración a un tercero privado con el que hubiera contratado o incluso le hubiera otorgado una subvención. En estos casos, entendemos que no debería ser aceptable que el alto cargo percibiese cantidad alguna, sobre todo en los casos en los que la Administración de la que depende es la que ha efectuado el contrato u otorgado la subvención (54).

Por este motivo, de lege ferenda proponemos adoptar la fórmula empleada en la Ley Baleares 2/1996 cuando dispone, en su artículo 7.b) in fine, que: "No obstante, la realización de estudios, de informes, de memorias, de investigaciones, de creaciones literarias, artísticas y similares será incompatible, aunque fuera solicitada o encargada por personas físicas o jurídicas privadas, si deben ser retribuidas con cargo a la Administración General del Estado o entidades dependientes de ella» (55)y (56).

\section{Colaboración y la asistencia ocasional y excepcional como ponente a congresos, seminarios, jornadas de trabajo, conferencias o cursos de carácter profesional}

El artículo 13.2.c/2. ${ }^{a}$ de la Ley $3 / 2015$, junto con las actividades de producción y creación literaria, artística..., excluye del régimen de incompatibilidades la colaboración y la asistencia como ponente a congresos, seminarios, jornadas de trabajo, conferencias o cursos de carácter profesional, siempre que no sean consecuencia de una relación de empleo o de prestación de servicios o supongan un menoscabo del estricto cumplimiento

(54) En la tramitación parlamentaria en el Congreso, el Grupo Parlamentario de IU, ICV-EUiA, CHA: La Izquierda Plural, en la enmienda 36 proponía un cambio de redacción del artículo 13.2.c)2. ${ }^{\text {a }}$, en el que se condicionaba la compatibilidad a que «... no perciban ningún tipo de retribución ni supongan un menoscabo del cumplimiento de sus deberes», aunque después en la justificación de la medida exclusivamente parecía ir referida a la colaboración y la asistencia ocasional y excepcional como ponente a congresos, seminarios, jornadas de trabajo, conferencias, etc.

(55) La cursiva es mía.

(56) El artículo 8.b) Ley Castilla y León 6/1998 (derogada por la Ley 3/2016), en un sentido similar, disponía que «El ejercicio de los cargos o puestos a que se refiere esta Ley es, además, incompatible: con la realización de estudios, informes, memorias, investigaciones, creaciones literarias, artísticas y similares cuando sean retribuidos con cargo a fondo de las Administraciones Públicas o de Entidades dependientes de ellas o cuando se originen como consecuencia de una relación de empleo o prestación de servicios». En la nueva ley no aparece un precepto de esta naturaleza y exclusivamente se prevé, en relación a esta cuestión, la compatibilidad con las actividades de producción y creación literaria, artística, científica o técnica y las publicaciones derivadas de las mismas [art. 7.2.a)]. 
de sus deberes(57). Pero para que se produzca esta compatibilidad se requiere que la actividad tenga un carácter ocasional y excepcional, sin olvidar que no puede ser consecuencia de una relación de empleo o de prestación de servicios, ni suponer un menoscabo del estricto cumplimiento de sus deberes (58). Todo ello sin olvidar que este tipo de actividades deben ser privadas, pues en los casos en que el alto cargo asista como ponente a un acto de esta naturaleza con ocasión de su cargo debe entenderse que forma parte del desarrollo normal de su actividad y, por tanto, no tendría razón para ser excepcionada (59).

(57) Alguna Comunidad Autónoma ha previsto, al margen de esta participación ocasional como ponente a congresos, seminarios, jornadas de trabajo, conferencias o cursos de carácter profesional, la compatibilidad con la docencia universitaria siempre que no suponga un menoscabo en sus funciones, sea a tiempo parcial y generalmente se requiere autorización previa (p.ej. arts. 6 Ley Navarra 19/1996 o 7 Ley Canarias 3/1997). La Ley Galicia 1/2016 es amplia en este sentido en cuanto que se refiere al ejercicio de funciones docentes, de carácter reglado, cuando en su artículo 41, Compatibilidad con el ejercicio de la docencia, dispone que: "1. Se podrá compatibilizar, cumplidas las restantes exigencias de la presente ley, el ejercicio de funciones docentes, de carácter reglado, siempre que no supongan menoscabo de la dedicación en el ejercicio del cargo público y se realice en régimen de dedicación a tiempo parcial. 2. El desarrollo de esta actividad no podrá suponer en ningún caso incremento alguno sobre las cantidades que por cualquier concepto corresponda percibir por el ejercicio del cargo público, con excepción de las indemnizaciones por gastos de viajes, estancias y traslados que les correspondan de acuerdo con la normativa vigente en el área docente, y dándoles idéntico destino a los derechos económicos que, en su caso, pudiesen devengarse con arreglo a lo dispuesto en el artículo 40.2.3. Para el ejercicio de las funciones docentes se requerirá la autorización expresa de la persona titular de la consejería competente en materia de función pública. 4. Los altos cargos comprendidos en el ámbito de aplicación de este capítulo podrán participar en las actividades a cargo de los centros oficiales de formación y perfeccionamiento del personal empleado público mediante la impartición de conferencias y cursos, siempre que dicha colaboración se produzca con carácter excepcional, así como en los congresos, seminarios y actividades análogas, teniendo derecho a la percepción de las indemnizaciones previstas reglamentariamente. Los centros de formación dependientes de la Administración general de la Comunidad Autónoma y de los entes instrumentales del sector público autonómico comunicarán trimestralmente a las consejerías competentes en materia de presupuestos y de función pública el desglose de las cantidades satisfechas por los conceptos indicados.". La Ley Generalidad Valenciana 8/2016 procede a una regulación pormenorizada y huye del concepto de docencia universitaria para referirse, como la Comunidad Gallega, a la docencia reglada, cuando prevé que «El ejercicio del cargo será compatible con la realización de actividades docentes de carácter reglado, siempre que no sea en detrimento de la dedicación al ejercicio del cargo público, se realicen en régimen de dedicación a tiempo parcial y, en todo caso, con un límite no superior a las 60 horas lectivas anuales, y siempre que la retribución que se perciba no supere el 30 \% que les corresponde por razón del cargo. El ejercicio de las funciones docentes requiere la autorización expresa de la Oficina de Control de Conflictos de Intereses" (art. 7.3). En el caso de la Ley País Vasco 1/2014 se prevé, en relación a la declaración de actividades, que "la declaración relativa al ejercicio de las actividades docentes que vinieran desempeñando o que estuvieran comprometidas con anterioridad al inicio de la relación de servicio como cargo público se realizará antes de esta, quedando en suspenso la toma de posesión hasta que el Consejo de Gobierno se pronuncie sobre la compatibilidad" - art. 20.3-.

(58) Véanse también, entre otros, los artículos 8.1.b) Ley Cataluña 13/2005; 7 Ley Baleares 2/1996; y 8.1 Ley Canarias 3/1997; 11.b) Ley Cantabria 1/2008; 41.1 Ley Galicia 1/2016; 7.2.b) Ley Castilla y León 3/2016; 7 Ley Madrid 14/1995; 6 Ley Navarra 19/1996 o 14.b) Ley País Vasco 1/2014.

(59) La Ley Cataluña 13/2005, en el artículo dedicado a las actividades privadas compatibles, distingue a) La participación ocasional en seminarios, cursos, conferencias, coloquios y programas de cualquier medio de comunicación social, siempre y cuando no sea consecuencia de una relación 
El requisito del carácter ocasional exigido por la Ley para que este tipo de actividades resulte compatible es común en el escenario de la normativa autonómica de incompatibilidad y de conflicto de intereses de los altos cargos, todo ello en la medida que como ha señalado el Tribunal Constitucional este elemento, en relación con el Régimen de incompatibilidad de los empleados públicos (60) «es perfectamente razonable y coherente con el sistema de incompatibilidades (...), ya que de no existir esa limitación, el ejercicio habitual, reiterado y constante de la actividad podría entrar en contradicción con la dedicación al puesto de trabajo en la Administración, con menoscabo de la eficacia de la actividad correspondiente» (61).

Sin embargo, debemos observar que la Ley $3 / 2015$, siguiendo el criterio de la Ley 5/2006, introduce junto con el carácter ocasional, el de excepcional (62), requisito que no tiene paragón en ninguna norma auto-

\begin{abstract}
de trabajo o de prestación de servicios y b) La participación en seminarios, jornadas o conferencias organizadas por centros oficiales destinados a la formación del personal de las administraciones públicas catalanas, siempre y cuando no tenga carácter permanente o habitual y participen en los mismos por razón del cargo que ocupan, de su especialidad profesional o de la posición que ocupan en la organización administrativa de la Generalidad - art. 8.1.b) y c) - a los que aplica el mismo régimen cuando desde nuestra perspectiva son supuestos distintos que deberían tener regímenes distintos. Pues en el segundo caso nos hallamos ante cursos organizados y financiados por la Administración, y aunque los altos cargos puedan participar aportando sus conocimientos y experiencia, no es razonable que puedan ser retribuidos por ello. Véase en un sentido similar el art. 7 bis $a$ ) y b). Actividades docentes, culturales y científicas en los ámbitos público o privado, Ley Baleares 2/1996. En Canarias se prevé que el desempeño de un alto cargo será compatible con la impartición y dirección de seminarios, cursos y conferencias en centros oficiales destinados a la selección, formación y perfeccionamiento de funcionarios, siempre que no tengan carácter permanente o habitual ni supongan más de setenta y cinco horas al año" - art. 7.2 Ley Canarias 3/1997-. Pero en este campo, el texto más claro es el artículo 17 de la Ley País Vasco 1/2014. - Compatibilidad con el ejercicio de la docencia universitaria y con la formación de empleados públicos, cuando dispone que: «1.-Los cargos públicos incluidos en el ámbito de aplicación de la presente ley podrán compatibilizar sus funciones con el ejercicio retribuido de la docencia en la enseñanza universitaria, siempre que no suponga detrimento de su dedicación y, en todo caso, con un límite no superior a las sesenta horas lectivas anuales. 2.-Asimismo, y con los mismos límites señalados en el apartado anterior, podrán participar en seminarios, jornadas o conferencias organizadas por centros oficiales destinados a la formación del personal de las administraciones públicas, siempre y cuando no tenga carácter permanente y participen en los mismos por razón del cargo que ocupen, de su especialidad profesional o de la posición que ocupen en la organización administrativa del sector público». Resulta interesante la previsión del Acuerdo 132/2015, de 15 de octubre, de la Junta de Castilla y León, por el que se aprueba la renovación y ampliación del Código Ético y de Austeridad de los altos cargos de la Administración de la Comunidad de Castilla y León y de sus entes adscritos cuando manifiesta que: "Los altos cargos harán pública su participación como ponentes en congresos, seminarios, jornadas de trabajo, conferencias o cursos, siempre que su participación se efectúe en su condición de alto cargo y renunciarán a las cantidades que les pueda corresponder por dicha participación».
\end{abstract}

(60) La Ley 53/1984, de 26 de diciembre, de Incompatibilidades del Personal de las Administraciones Públicas, en su artículo 19.h), Actividades exceptuadas del régimen de incompatibilidades, dispone que: "Quedan exceptuadas del régimen de incompatibilidades de la presente Ley las actividades siguientes: la colaboración y la asistencia ocasional a congresos, seminarios, conferencias o cursos de carácter profesional».

(61) STC núm. 178/1989 de 2 noviembre (RTC 1989\178).

(62) El carácter excepcional no se contenía en la Ley 12/1995 [art. 4.b)]. 
nómica y que entendemos que viene a reforzar el primer elemento, pues la interpretación resulta compleja a no ser que entendamos, en una visión forzada, que el carácter ocasional se predica del desarrollo de este tipo de actividades y la excepcionalidad, podría ir vinculada a la participación en varias ediciones de un mismo curso o congreso, en cuyo caso quedaría prohibida.

Un argumento que la Ley $3 / 2015$ no aborda es si los altos cargos pueden percibir remuneración por estas actividades. Lo que sí parece indicar es que no existe inconveniente alguno, sobre todo al entender, como hemos indicado, que nos hallamos ante actividades privadas (63). Con todo, en la tramitación parlamentaria en el Congreso, el Grupo Parlamentario de IU, ICV-EUiA, CHA: La Izquierda Plural, en la enmienda 36, proponía un cambio de redacción del artículo 13.2.c).2. ${ }^{a}$, en el que se condicionaba la compatibilidad a que «no perciban ningún tipo de retribución».

En estos casos, alguna Comunidad Autónoma, como es el caso de Andalucía exige que las mismas "no estén financiadas específicamente por la Administración de la Junta de Andalucía» - art. 4.b) Decreto Andalucía 176/2005-(64). Esta medida nos parece adecuada, a la vez que oportuna. Un alto cargo no debería poder participar en una actividad privada de esta naturaleza - recordemos que cuando es con ocasión de su cargo no debería percibir retribución alguna-, cuando ha sido la Administración quien lo ha organizado, financiado o promocionado, sobre todo en los casos en que la Administración sea la misma en la que aquél desarrolla su actividad.

(63) GARCÍA MEXÍA - Los conflictos de intereses, ob. cit., p. 159- ve con desconfianza la participación en este tipo de actos a cambio de retribuciones suculentas porque puede resultar peligrosa en orden a preservar la imparcialidad de los mismos, pues es frecuente que las retribuciones sean cuantiosas $y$, en numerosas ocasiones, estos actos están organizados y/o promovidos por colectivos interesados.

(64) Como mantuvimos en su momento - «Régimen de los altos cargos de la Administración de la Junta de Andalucía», en AA.VV. (coords. por S. FERNÁNDEZ RAMOS, J. M. PÉREZ MONGUIÓ) Estudios sobre el Gobierno y la Administración de la Junta de Andalucía, Sevilla, 2011, pp. 221-278«Una aplicación estricta del precepto llevaría a pensar que los altos cargos no podrían participar ni colaborar, en modo alguno, cuando la actividad se encuentre financiada por la Junta de Andalucía. Sin embargo, esta interpretación literal debe ser abandonada o desechada, pues debemos entender que el precepto se refiere exclusivamente a las actividades de esta naturaleza ajenas al cargo. No tendría sentido que un Consejero no pudiese pronunciar una conferencia financiada por su propia Consejería cuando su intervención se deba precisamente al cargo que ocupa, lo que no podría es percibir ingreso alguno en virtud de su intervención". 


\section{La participación en entidades culturales o benéficas}

La compatibilidad de la participación de altos cargos en entidades culturales, tiene su antecedente en el artículo 4.c) de la Ley 12/1995, compatibilidad que estaba condicionada por una parte a que aquellas no tuviesen ánimo de lucro, $y$, por otra, se exigía que aquel no percibiese ningún tipo de retribución o percepción por la actividad, todo ello sin olvidar que no debía comprometer la imparcialidad o independencia del alto cargo en el ejercicio de su función (65).

Esta actividad compatible no ha sufrido en las leyes posteriores una modificación conceptual y simplemente se han llevado a cabo mejoras técnicas de la misma, siempre en torno al concepto de retribución o compensación por el desarrollo de la actividad. Así, la Ley 5/2006 limitaba la retribución o percepción al límite previsto en el artículo 3.5 de la Ley 49/2002, de 23 de diciembre, que regula el régimen fiscal de las entidades sin fines lucrativos y de los incentivos fiscales al mecenazgo (66). El artículo 13.2.c).3. ${ }^{a}$ de la Ley $3 / 2015$ ha dado un paso más mejorando técnicamente las previsiones de la anterior. De esta manera se establece, como hacía la Ley 12/1995, la prohibición de retribución alguna, pero se prevé el derecho a ser reembolsados de los gastos que le origine, gastos que deberán ser debidamente justificados, todo ello conforme a lo previsto en el artículo 3.5 de la Ley 49/2002, de 23 de diciembre, de régimen fiscal de las entidades sin fines lucrativos y de los incentivos fiscales al mecenazgo (67).

(65) Algunas Comunidades Autónomas, como es el caso de Cataluña, no contemplan esta modalidad de excepción al régimen de incompatibilidad y solo se refieren a la participación en entidades sin ánimo de lucro - art. 8.1.e) Ley 13/2005. Otras Comunidades requieren que las entidades benéficas o culturales no tengan ánimo de lucro para poder reconocer la compatibilidad, como es el caso de la Comunidad Balear - art. 7.d) Ley 2/1996-, mientras que otras exigen la ausencia de ánimo de lucro y la ausencia de retribución alguna-arts. 56.c) Ley La Rioja 8/2003; 42.1.c) Ley Galicia 1/2016 8.1 Ley Canarias 3/1997; 6 Ley Navarra 19/1996; 14.d) Ley País Vasco 1/2014. La Ley Baleares 2/1996 contiene una causa de compatibilidad no prevista expresamente en ninguna norma sobre la materia. Nos referimos a la "participación, como voluntario, en actividades solidarias de entidades benéficas sin ánimo de lucro, siempre que no comporten ningún tipo de menoscabo del cumplimiento de los deberes o las funciones correspondientes" - art. 7.c)-. Véase, sobre el tratamiento de esta causa en la Comunidad Autónoma de Andalucía, J. M. ${ }^{a}$ PÉREZ MONGUIÓ, «Régimen de los altos cargos de la Administración de la Junta de Andalucía", en AA.VV (coord. por S. FERNÁNDEZ RAMOS, J. M. ${ }^{a}$ PÉREZ MONGUIÓ), Estudios sobre el Gobierno y la Administración, de la Junta de Andalucía, Sevilla, 2011, pp. 238-239.

(66) Véase artículo 10.c) Ley 5/2006.

(67) Art. 3.5 Ley 49/2002, de 23 de diciembre, de régimen fiscal de las entidades sin fines lucrativos y de los incentivos fiscales al mecenazgo: "Las entidades a que se refiere el artículo anterior, que cumplan los siguientes requisitos, serán consideradas, a efectos de esta Ley, como entidades sin fines lucrativos: $5 .^{\circ}$ Que los cargos de patrono, representante estatutario y miembro del órgano de gobierno sean gratuitos, sin perjuicio del derecho a ser reembolsados de los gastos debidamente justificados que el desempeño de su función les ocasione, sin que las cantidades percibidas por este concepto puedan exceder de los límites previstos en la normativa del Impuesto sobre la Renta 
El mayor problema que se deriva de la presente causa de compatibilidad es la definición de "participación", pues resulta un concepto jurídico indeterminado. En este sentido la única Comunidad Autónoma que ha previsto la naturaleza de la participación ha sido la cántabra, cuando la Ley Cantabria 1/2008 manifiesta, en su artículo 11.c): "La participación como patrono, representante estatutario o miembro del órgano de gobierno en entidades culturales o benéficas que no tengan ánimo de lucro o fundaciones, siempre que no perciban ningún tipo de retribución o percepción por dicha participación, y sin perjuicio de su derecho a ser reembolsados de los gastos debidamente justificados que el desempeño de su función les ocasione. Las cantidades percibidas por este concepto no podrán exceder de los límites previstos en la normativa sobre impuesto de la renta de las personas físicas para ser consideradas dietas exceptuadas de gravamen", que como puede apreciarse es una reproducción del artículo 3.5 de la Ley 49/2002, de 23 de diciembre, de régimen fiscal de las entidades sin fines lucrativos y de los incentivos fiscales al mecenazgo.

\section{Bibliografía}

CERRILLO I MARTÍNEZ, A., "Los conflictos de intereses y los actos de integridad: la prevención de la corrupción en los contratos públicos», en AA.VV., La corrupción en España, Atelier, Barcelona, 2016, pp. 185-212. FERNÁNDEZ RAMOS, S. y PÉREZ MONGUIÓ, J. M. ${ }^{a}$, Transparencia, acceso a la información pública y buen gobierno. Thomson-Reuter Aranzadi, Cizur Menor, 2014.

GARCÍA MEXÍA, P., Los conflictos de intereses y la corrupción contemporánea. Aranzadi, 2001.

\footnotetext{
de las Personas Físicas para ser consideradas dietas exceptuadas de gravamen. Lo dispuesto en el párrafo anterior no resultará de aplicación a las entidades a que se refiere el párrafo e) del artículo anterior y respetará el régimen específico establecido para aquellas asociaciones que, de acuerdo con la Ley Orgánica 1/2002, de 22 de marzo, Reguladora del Derecho de Asociación, hayan sido declaradas de utilidad pública. Los patronos, representantes estatutarios y miembros del órgano de gobierno podrán percibir de la entidad retribuciones por la prestación de servicios, incluidos los prestados en el marco de una relación de carácter laboral, distintos de los que implica el desempeño de las funciones que les corresponden como miembros del Patronato u órgano de representación, siempre que se cumplan las condiciones previstas en las normas por las que se rige la entidad. Tales personas no podrán participar en los resultados económicos de la entidad, ni por sí mismas, ni a través de persona o entidad interpuesta. Lo dispuesto en este número será de aplicación igualmente a los administradores que representen a la entidad en las sociedades mercantiles en las que participe, salvo que las retribuciones percibidas por la condición de administrador se reintegren a la entidad que representen. En este caso, la retribución percibida por el administrador estará exenta del Impuesto sobre la Renta de las Personas Físicas y no existirá obligación de practicar retención a cuenta de este impuesto".
} 
JIMÉNEZ BLANCO, A., «Estatuto de los miembros del Gobierno: deberes, derechos e incompatibilidades", en AA. VV. (Coord. L. PAREJO ALFONSO), Estudios sobre el Gobierno. Universidad Carlos III y BOE, Madrid, 1996.

JUSTO MEGÍAS OUIRÓS, J., "Regeneración democrática de los altos cargos", en A. TRONCOSO REIGADA, Comentario a la Ley de Transparencia, Acceso a la Información Pública y Buen Gobierno. Civitas-Thomson Reuter, 2017, pp. 1505 a 1528.

MESEGUERYEBRA, J., Conflictos de Intereses e incompatibilidades de los miembros del Gobierno y Altos Cargos de la Administración. Bosch, Barcelona, 2007.

PÉREZ MONGUIÓ, J. M. ${ }^{a}$, "Régimen de los altos cargos de la Administración de la Junta de Andalucía», en AA.VV (coords. por S. FERNÁNDEZ RAMOS, J. M. ${ }^{a}$, PÉREZ MONGUIÓ) Estudios sobre el Gobierno y la Administración de la Junta de Andalucía. Sevilla, 2011, pp. 221-278. "Deberes de los altos cargos andaluces en ejercicio", en Administración de Andalucía: Revista andaluza de Administración Pública, núm. 80, 2011, pp. 115-146.

PÉREZ MONGUIÓ, J. M. a y FERNÁNDEZ RAMOS, S., El Estatuto de los altos cargos. Thomson Reuter, 2016.

SARMIENTO MÉNDEZ, X. A., "As incompatibilidades dos membros da Xunta e demáis altos cargos», en Revista Xurídica de la Universidad de Santiago de Compostela, núm. 1 (1996).

SERRANO PÉREZ, M. ${ }^{a}, M$. , "Los principios de actuación del buen gobierno", en A. TRONCOSO REIGADA, Comentario a la Ley de Transparencia, Acceso a la Información Pública y Buen Gobierno. Civitas-Thomson Reuter, 2017, 1529-1565. 
LABURPENA: Oinarrizko zutabe batzuen arabera joan dira garatzen eta ezartzen goi-kargu baten jarduera garatzeko esparrua eratzen duten printzipioak eta eskakizunak. Goi Karguen Bateraezintasunei buruzko abenduaren 26ko 25/1983 Legean jaso dira horietako batzuk, hastapenetan batzuk; hala nola, beste askoren artean, inpartzialtasuna, erabateko arduraldia eta ordainsari bakarra, hori guztia administrazio onaren printzipioaren esparruan kokatuta.

Bada, laurogeigarren hamarkadako Goi Karguen Bateraezintasunei buruzko Legean salbuespen batzuk jaso dira, eta, horiekin, printzipio batzuk arindu ahal izan dira (arduraldiarena eta ordainsari bakarrarena, adibidez). Bestetik, salbuespen horiei esker, karguarekin bateragarri izan daitezkeen jarduera jakin batzuk garatzea erraztu da, eta publikoetan eta pribatuetan sailkatu dira jarduera horiek.

Goi-karguen jarduera pribatu bateragarrien araubidea aztertu nahi izan da lan honekin, Estatuko Administrazio Orokorreko goi-karguen jarduna arautzen duen martxoaren 30eko 3/2015 Legea hartuta euskarritzat.

GAKO HITZAK: Goi-karguak. Gobernu ona. Jarduera pribatu bateragarria. Norberaren ondarea administratzea. Balio finantzarioak. Sozietate-partaidetzak. Ekoizpen artistikoa. Hizlari gisa aritzea.

RESUMEN: El ejercicio de la actividad de un alto cargo se desarrolla en el marco de un conjunto de principios y exigencias que se han ido desarrollando e implementando desde unos pilares básicos, ya recogidos, en algún caso de forma embrionaria, en la Ley 25/1983, de 26 de diciembre, sobre incompatibilidades de altos cargos, como son, entre otros muchos, los de imparcialidad, dedicación exclusiva, retribución única y todo ello en el marco del principio de Buena Administración.

Con todo, desde la Ley de incompatibilidades de los altos cargos de los años ochenta se han venido contemplando excepciones que permiten atenuar algunos principios como el de dedicación y retribución única, y facilitan el desarrollo de ciertas actividades que pueden compatibilizarse con el desarrollo del cargo y que se han clasificado en públicas y privadas.

El objeto de este trabajo es el análisis del régimen de las actividades compatibilidades privadas de los altos cargo, tomando como piedra angular la Ley $3 / 2015$, de 30 de marzo, reguladora del ejercicio del alto cargo de la Administración General del Estado.

PALABRAS CLAVE: Altos cargos. Buen gobierno. Actividad compatible privada. Administración patrimonio personal. Valores financieros. Participaciones societarias. Producción artística. Colaboración como ponente.

ABSTRACT: The exercise of activity by a senior official is to be developed within the framework of a set of principles and requirements which have progressed and been implemented from some fundamental pillars, already established, in some cases in a very embryonic form, by Act $28 / 1983$ of December $26^{\text {th }}$, on incompatibilities of senior officials as they are, among many, the impartiality, full- 
time dedication, sole remuneration and all of it within the framework of the good administration principle.

However, since Act on incompatibilities of senior officials in the eighties many exceptions have been envisioned which allow to mitigate some principles like fulltime dedication and sole remuneration, and they ease the development of some activities which could be made compatible with the exercise of the activity and that have been classified as public and private.

The scope of this work is to analyze the regime for private compatible activities of senior officials taking as cornerstone Act 3/2015 of March 30th, on the exercise of activities by senior officials within the central state administration.

KEYWORDS: Senior officials. Good governance. Private compatible activity. Personal wealth management. Financial securities. Corporate investments. Artistic production. Collaboration as speaker. 